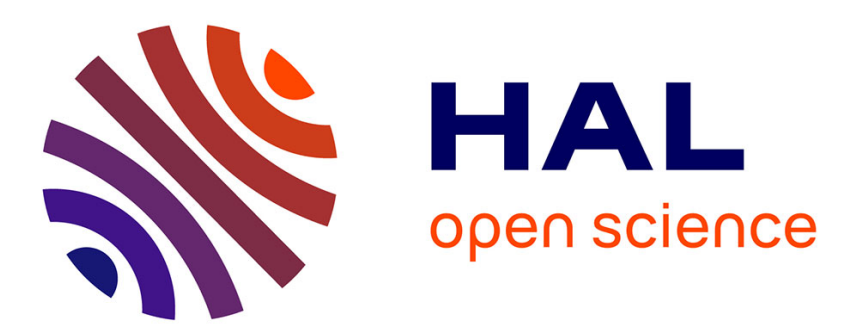

\title{
Mechanism and regulation of class switch recombination by IgH transcriptional control elements
}

\author{
Chloé Oudinet, Fatima-Zohra Braikia, Audrey Dauba, Ahmed Amine
}

Khamlichi

\section{- To cite this version:}

Chloé Oudinet, Fatima-Zohra Braikia, Audrey Dauba, Ahmed Amine Khamlichi. Mechanism and regulation of class switch recombination by $\mathrm{IgH}$ transcriptional control elements. Advances in immunology, 2020, 147, pp.89 - 137. 10.1016/bs.ai.2020.06.003 . hal-03428266

\section{HAL Id: hal-03428266 \\ https://hal.science/hal-03428266}

Submitted on 17 Nov 2021

HAL is a multi-disciplinary open access archive for the deposit and dissemination of scientific research documents, whether they are published or not. The documents may come from teaching and research institutions in France or abroad, or from public or private research centers.
L'archive ouverte pluridisciplinaire HAL, est destinée au dépôt et à la diffusion de documents scientifiques de niveau recherche, publiés ou non, émanant des établissements d'enseignement et de recherche français ou étrangers, des laboratoires publics ou privés. 


\section{Mechanism and regulation of class switch recombination}

\section{by IgH transcriptional control elements}

Chloé Oudinet, Fatima-Zohra Braikia, Audrey Dauba, and Ahmed Amine Khamlichi*

Institut de Pharmacologie et de Biologie Structurale, IPBS, Université de Toulouse, CNRS, Université Paul Sabatier, 31077 Toulouse, France.

* Corresponding author : ahmed.khamlichi@ipbs.fr

ORCID : 0000-0002-6523-2035 


\section{Contents}

1. Overview of class switch recombination

2. Role of $I g H$ Transcriptional control elements

2.1. 5' hypersensitive sites

2.2. The E $\mu$ enhancer

2.3. The $I g H$ super-enhancer : the $3^{\prime}$ Regulatory Region

2.3.1. The $3^{\prime} R R$ and locus suicide recombination

2.3.2. The $3^{\prime} R R$ and class switch recombination to $\lg D$

2.3.3. The $3^{\prime} R R$ and class switch recombination in $B 1$ B-cells

2.4. The $3^{\prime} \gamma 1 \mathrm{E}$ enhancer

2.5. CTCF binding elements

2.5.1. The 3'CTCF binding elements

2.5.2. The 5 'sh1RI insulator

3. Class switch recombination in the $\mathrm{CH} 12 \mathrm{~F} 3$ cell line

4. Class switch recombination in developing B cells

5. Mechanism and regulation of class switch transcription by $\mathrm{IgH}$ control elements

5.1. Competition versus coactivation

5.2. Transcriptional and epigenetic regulation by the 3 ' Regulatory Region

5.3. Long-range interactions at the $\mathrm{IgH}$ constant region

5.4. Loop extrusion and class switch recombination centre

6. The IncCSR ${ }^{I g A}$ locus

7. Perspectives

8. Acknowledgments

9. Compliance with ethics guidelines

10. References 


\section{Abstract}

Class switch recombination (CSR) plays an important role in humoral immunity by generating antibodies with different effector functions. CSR to a particular antibody isotype is induced by external stimuli, and occurs between highly repetitive switch (S) sequences. CSR requires transcription across $S$ regions, which generates long non-coding RNAs and secondary structures that promote accessibility of $\mathrm{S}$ sequences to activation-induced cytidine deaminase (AID). AID initiates DNA double-strand breaks (DSBs) intermediates that are repaired by general DNA repair pathways. Switch transcription is regulated by various regulatory elements, including enhancers and insulators. The current paradigm posits that transcriptional control of CSR involves long-range chromatin interactions between regulatory elements and chromatin loops-stabilizing factors, which promote alignement of partner S regions in a CSR centre (CSRC) and initiation of CSR. In this review, we focus on the role of $I g H$ transcriptional control elements in CSR and the chromatin-based mechanisms underlying this control.

Keywords : B lymphocyte - IgH locus - Class switch recombination - Switch transcription Enhancer - promoter - Insulator - Long-range interactions - Loop extrusion - Chromatin 


\section{Abbreviations}

3'RR 3' regulatory region

AID activation-induced cytidine deaminase

$\mathrm{C}_{\mathrm{H}} \quad \mathrm{IgH}$ constant gene

CSR class switch recombination

CSRC class switch recombination centre

CBE CTCF binding element

GLT germline/switch transcription

IL4 interleukin 4

IL7 interleukin 7

IRIS inverted repeated intervening sequence

LPS lipopolysaccharide

SHM somatic hypermutation

TGF- $\beta$ transforming growth factor- $\beta$ 


\section{Overview of class switch recombination}

The B lymphocytes have a remarkable capacity to somatically alter their Ig loci. In developing B cells, the primary antibody repertoire is generated through $V(D) J$ recombination, which targets the variable region of their immunoglobulin heavy chain $(I g H)$ and Ig light chain $(\lg L)$ loci, and is catalysed by the RAG1/RAG2 complex (Jung et al., 2006; Khamlichi and Feil, 2018; Kumari and Sen, 2015; Lin et al., 2018; Proudhon et al., 2015; Teng and Schatz, 2015). Upon antigen challenge, mature B cells have the unique ability to further diversify their antibodies through additional genomic alterations: somatic hypermutation (SHM) and class switch recombination (CSR). Both SHM and CSR are initiated by AID and require transcription of the target sequences. SHM targets the variable regions of $\operatorname{lgH}$ and $\lg \mathrm{L}$ genes, ultimately leading to antibodies with higher affinity (Di Noia and Neuberger, 2007; Maul and Gearhart, 2010; Muramatsu et al., 2007; Pavri and Nussenzweig, 2011; Peled et al., 2008; Storck et al., 2011; Yeap and Meng, 2019). CSR targets exclusively the constant $\left(C_{H}\right)$ genes of the $\lg H$ locus, enabling a change of the constant domains of Ig heavy chains, and therefore the effector functions of antibodies (Chaudhuri and Alt, 2004; Stavnezer et al., 2008). In this review, we discuss mainly studies of CSR in the mouse.

The mouse $\mathrm{IgH}$ locus can be divided into two main regions: an $\sim 2.2 \mathrm{Mb}$ variable region containing clusters of variable $\left(V_{H}\right)$ gene segments, a dozen of diversity $\left(D_{H}\right)$ and 4 joining $\left(\mathrm{J}_{H}\right)$ segments, and an $\sim 200 \mathrm{~kb} C_{H}$ region harboring $8 C_{H}$ genes, each specifying an Ig isotype $\left(5^{\prime}-C \mu\right.$, $C \delta, C \gamma 3, C \gamma 1, C \gamma 2 b, C \gamma 2 a, C \varepsilon$, and $\left.C \alpha-3^{\prime}\right)$ (Johnston et al., 2006; Retter et al. 2007) (Fig. 1A). At the cellular level, CSR enables antigen-activated B cells to switch from the expression of $\operatorname{Ig} \mathrm{M}$ to the expression of downstream isotypes (IgG, IgE or $\lg A$ ). At the genomic level, CSR occurs between evolutionary conserved, highly repetitive switch (S) sequences, located upstream of the $C_{H}$ genes (Fig. 1A). Except for $C \delta$ (discussed below), the $C_{H}$ genes are 
structurally similar transcription units made up of an I promoter immediately followed by an I exon upstream of S regions and the $C_{H}$ exons (Chaudhuri and Alt, 2004; Stavnezer et al., 2008, Yu and Lieber, 2019) (Fig. 1B). While I promoters have typically no enhancer function, I $\mu$ promoter is particular in that it overlaps with an enhancer $(E \mu / l \mu)(C h a u d h u r i$ and Alt, 2004; Stavnezer et al., 2008). Transcription from I $\mu$ is constitutive (Li et al., 1994; Rajagopal et al., 2009), while transcription from downstream I promoters is inducible. The choice of downstream I promoters depends on the extracellular signals (antigen, cytokine, mitogen, inter-cellular interactions) received by the B cell. These signals mobilize different signaling pathways, and ultimately lead to the recruitment of a specific set of transcription factors that suppress or induce transcription from an I promoter (Chaudhuri et al., 2007; Chen and Wang, 2019; Methot and Di Noia, 2017; Stavnezer et al., 2008; Yu and Lieber, 2019). Germline or switch transcription (GLT) is regulated by various cis-acting elements, including enhancers and insulators (Fig. 1), described in detail below.

The $S$ sequences vary in size, from the shortest $(\sim 1 \mathrm{~kb}$ for $S \varepsilon)$ to the largest ( 10 kb for $S \gamma 1)$, and contain characteristic repeated motifs including AID target motifs (Chaudhuri and Alt, 2004; Stavnezer et al., 2008, Yu and Lieber, 2019). Transcription through S regions targets AID activity, which initiates DNA cleavage at the universal donor $\mathrm{S} \mu$ region and the activated downstream S region. AID initiates DNA breaks by deaminating exposed cytosines into uracils which are recognized by base excision and mismatch repair pathways, ultimately leading to DSB intermediates. The DSBS are monitored by components of DNA damage response pathway, and are repaired by the classical and alternative non-homologous end joining pathways (Boboila et al. 2012; Daniel and Nussenzweig, 2013; Stavnezer et al., 2010).

Given the large distance between $\mathrm{S} \mu$ and downstream partner $\mathrm{S}$ regions, ranging from $\sim 50 \mathrm{~kb}$ (between $S \mu$ and $S \gamma 3$ ) to up to $200 \mathrm{~kb}$ (between $\mathrm{S} \mu$ and $\mathrm{S} \alpha$ ), CSR clearly involves long-range interactions that juxtapose the partner $S$ sequences. In the past few years, important 
advances were achieved along two axes, which are the focus of this review: the identification of new regulatory elements and characterization of their role in CSR, and the elucidation of the long-range chromatin-based mechanisms that control CSR.

Other crucial aspects of GLT and CSR were reviewed in detail, and will therefore not be dealt with here. This concerns 1 ) the multiple transcription factors that bind $\lg H$ elements with known or suspected function (Atchison, 2014; Birshtein, 2014; Ernst and Smale, 1995; Khamlichi et al., 2000; Pinaud et al., 2011), and will only be mentioned when pertinent, 2) the role of secondary structures such as R loops and G quadruplexes in promoting accessibility of $S$ sequences to AID and the involvement of the RNA-exosome surveillance machinery in the process (Basu et al., 2011; Ribeiro Di Almeida et al., 2018; Qiao et al., 2017; Wiedemann et al., 2016; Yu et al., 2003; Zheng et al., 2015. Reviewed in Maizels and Gray, 2013; Matthews et al., 2014; Nair et al., 2020; Pavri, 2017; Yu and Lieber, 2019), and 3) the repair pathways involved from AID-initiated lesions to the resolution phase of CSR (Boboila et al. 2012; Casellas et al., 2016; Daniel and Nussenzweig, 2013; Stavnezer et al., 2010).

\section{Role of IgH Transcriptional control elements}

Given the size of the $\mathrm{IgH}$ locus and the major architectural reorganization of the locus at different stages of B cell development that bring into proximity distant sequences, it will come as no surprise that the transcriptional elements potentially involved in CSR could be scattered along the $\mathrm{IgH}$ locus, provided they are preserved from a deletional event during $\mathrm{V}(\mathrm{D}) \mathrm{J}$ recombination. As discussed below, the crucial elements involved in CSR are confined within the $C_{H}$ region, but there may be exceptions. In this section, we summarise current knowledge on the role of these elements in GLT and CSR as revealed by targeted deletion and insertion studies. We focus on recent work on the role of enhancers and insulators. Earlier studies on 
the role of I promoters have been reviewed (Khamlichi et al., 2000; Perlot and Alt, 2008; Pinaud et al., 2011; Stavnezer, 2000).

\subsection{5' hypersensitive sites}

A cluster of four DNase I hypersensitive sites (hss), termed hs1, hs2, hs3a and hs3b, was identified $\sim 30 \mathrm{~kb}$ upstream of the most $5^{\prime} \mathrm{V}_{\mathrm{H}}$ gene segment (Pawlitzky et al., 2006) (Fig. 2). One site, hs1, was shown to be pro-B specific, and to bind PU.1, PAX5, and E2A transcription factors, which play an important role in various aspects of $V(D) J$ recombination. The hs1 element exhibited a modest repressive transcriptional activity in transient transfection assays (Pawlitzky et al., 2006). Given the position of the cluster at the $5^{\prime}$ end of the $\operatorname{lgH}$ locus, it was tempting to attribute to the cluster an important role in $V(D) J$ recombination and in the 3D architecture of the locus through interaction with other $\mathrm{IgH}$ elements (Pawlitzky et al., 2006) that might have an effect on CSR. The potential function of the cluster was investigated through targeted deletion in mice (Perlot et al., 2010). Deletion of hs1 alone or of the whole cluster had no apparent effect on B cell development, V(D)J recombination or CSR (Perlot et al. 2010) (Fig. 2, and associated table).

Thus, even if preserved from deletion events associated with $V(D) J$ recombination, the $5^{\prime}$ cluster does not appear to be involved in any of the major processes that occur within the $\mathrm{IgH}$ locus.

\subsection{The $E \mu$ enhancer}

A major control element in the $I g H$ locus is the $\mathrm{E} \mu$ enhancer located downstream of the $J_{H}$

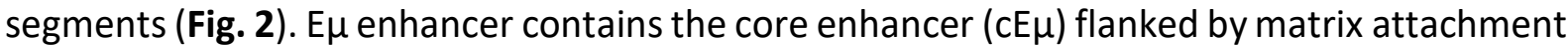
regions (MARs), I $\mu$ transcription start sites lie within the 3'MAR (Ernst and Smale, 1995; Khamlichi et al., 2000; Kumari and Sen, 2015; Perlot and Alt, 2008; Roy et al., 2011). While the 
critical role of $\mathrm{E} \mu$ enhancer in the control of $\mathrm{V}(\mathrm{D}) \mathrm{J}$ recombination is well established (Afshar et al., 2006; Bolland et al., 2007; Chakraborty et al., 2009; Perlot et al., 2005; Puget et al., 2015), its role in CSR is less apparent as deletion of $\mathrm{CE} \mu$ or $E \mu$ enhancer had only a modest effect on CSR (Marquet et al., 2014; Perlot et al., 2005; Sakai et al., 1999). Deletion of cE $\mu$ markedly reduced I $\mu$ transcript levels (Perlot et al., 2005) but had no apparent effect on GLT of acceptor S regions (Wuerfell et al., 2007), or on IgH isotype serum levels and surface Ig expression, though a modest effect on CSR was seen on the nonexpressed allele in hybridomas (Perlot et al., 2005; Sakai et al., 1999) (Fig. 2). E $\mu$-deleted mice had slightly reduced IgG1 serum levels, but exhibited normal response upon immunisation (Marquet et al., 2014).

The modest effect of $E \mu$ on CSR is somewhat intriguing because $E \mu$ enhancer activates $S \mu$, the universal switch donor site and, as discussed below, it engages in stable interactions with the 3'RR and other elements that are essential to CSR.

\subsection{The IgH super-enhancer: the 3' Regulatory Region}

The major control element of CSR is a super-enhancer (Whyte et al., 2013), termed 3' regulatory region ( $\left.3^{\prime} \mathrm{RR}\right)$, lying downstream of the $\operatorname{lgH}$ locus. The $3^{\prime} \mathrm{RR}(\sim 28 \mathrm{~kb})$ is composed of four B cell-specific enhancers, hs3a, hs1,2, hs3b, and hs4, that act in synergy. The hs1,2 enhancer is flanked by inverted repeated intervening sequences (IRISs) and lies at the centre of a large palindromic region bordered by two inverted copies of hs 3 enhancer, hs3a and hs3b, while hs4 enhancer is located outside of the palindrome (Birshtein, 2014; Khamlichi et al., 2000; Pinaud et al., 2011) (Fig. 2).

Recent studies revealed that the $3^{\prime}$ RR displays a multifaceted activity during $B$ cell development. The $3^{\prime} R R$ mediates a silencing of GLT associated with $V(D) J$ recombination (Braikia et al., 2015; Ghazzaui et al., 2019), this silencing activity is switched off upon completion of $\mathrm{V}(\mathrm{D}) \mathrm{J}$ recombination (Braikia et al., 2015). The $3^{\prime} \mathrm{RR}$ then shifts to a constitutive 
enhancer whose activity is likely directed by hs4 enhancer (Braikia et al., 2015; Braikia et al., 2017; Garot et al., 2016), and is induced in activated mature B cells where it controls SHM and CSR (Cogné et al., 1994; Rouaud et al., 2013) (Fig. 3). Here, we focus on the role of the 3'RR in CSR.

Targeted deletion of any of the four enhancers had no measurable effect on B cell proliferation, GLT, CSR, Ig serum isotype production or antigen-specific responses, revealing a redundancy between these elements (Bébin et al., 2010; Manis et al., 1998; Vincent-Faber, 2009). In contrast, combined deletion of hs3b/hs4 severely impaired GLT and CSR to all isotypes with the notable exception of IgG1, which was only modestly reduced (Pinaud et al., 2001). Deletion of the whole 3'RR virtually inhibited GLT of and CSR to all isotypes except for S $\gamma 1$ GLT and CSR to IgG1, which, though reduced, were readily detectable. Interestingly, S $\mu \mathrm{GL}$ transcript levels were also reduced upon deletion of the $3^{\prime} R R$, but the reduction was moderate compared to downstream S regions (Vincent-Faber et al., 2010) (Fig. 2).

In an attempt to evaluate the contribution of the enhancers themselves versus the global structure of the $3^{\prime} R R$, in particular with respect to its palindrome, further dissection of the $3^{\prime} \mathrm{RR}$ was performed by generating various mouse models. Thus, a large deletion removing the proximal hs3a-left IRIS-hs1,2 region (Fig. 2) impaired S $\gamma 3$, S $\gamma 2$ b and S $\gamma 2 a$ GLT and CSR to IgG3, $\operatorname{IgG2b}$ and IgG2a. S $\gamma 1$ GLT was not significantly impacted but IgG1 surface expression was reduced. In contrast, S $\alpha$ GLT and surface expression of IgA were unaffected. Ig production of all isotypes was significantly reduced in vitro, while only IgG3 and IgG2a serum levels were reduced (Saintamand et al., 2015). In another mouse model, the left IRIS alone was deleted leaving intact hs3a and hs1,2 enhancers, though the remaining hs3a was in opposite orientation to its endogenous position. In this context, deletion of the left IRIS had no effect on GLT or surface expression of Ig isotypes except for $5 \gamma 2 a$ GLT and IgG2a surface expression, which were reduced. Production of $\operatorname{IgG} 1, \lg G 2 \mathrm{~b}$ and $\operatorname{IgG} 2 \mathrm{a}$ was reduced in vitro, while in vivo, 
only IgG3 and IgG2a serum titers were reduced (Saintamand et al., 2015). Overall, inclusion of hs3a and hs1,2 in the large proximal deletion had a stronger effect on GLT and CSR than deletion of the IRIS alone, the latter preferentially targeting S $\gamma 2 \mathrm{a}$.

As mentioned previously, individual deletion of any $3^{\prime} R R$ enhancer had no effect, while combined deletion of two enhancers led to a strong reduction of GLT and CSR to most isotypes. One could anticipate that deleting an additional enhancer will lead to a more severe effect. Somewhat surprisingly, that was not exactly the case. Deletion of the whole palindrome including hs3a, hs1,2 and hs3b enhancers impaired S $\gamma 3$ GLT and, to a lesser extent, S $\gamma 1$ and $S \gamma 2 a$ GLT, and CSR to the corresponding isotypes, while $S \gamma 2 b$ and $S \alpha$ GLT and CSR to IgG2b and IgA remained unaffected (Garot et al., 2016) (Fig. 2).

As a necessary complement to the above mutations, the whole endogenous $3^{\prime} \mathrm{RR}$ was replaced by the four core enhancers (Lenoir et al., 2017). Surprisingly, the defect in GLT of all isotypes was overall intermediate between wild type and $3^{\prime}$ RR-deficient B cells. Accordingly, B cells with the core $3^{\prime}$ RR could not support wild type levels of CSR except for IgG1 (Lenoir et al., 2017) (Fig. 2). Thus, with respect to GLT and CSR, the palindrome appears to be required for efficient CSR.

However, a potential caveat in these studies relates to the transcriptional activity of the $3^{\prime} \mathrm{RR}$ itself and its long-range interactions. Upon B cell activation, $3^{\prime} \mathrm{RR}$ is actively transcribed and eRNAs production correlates with its activity (Braikia et al., 2015; Delgado-Benito et al., 2018; Péron et al., 2012). It is unclear to what extent a large deletion of an IRIS for instance or a close alignement of the core enhancers affects $3^{\prime}$ RR eRNAs structure and function. It is arguable that the phenotype results from missing or destabilized eRNAs rather than from the absence of an IRIS perse. Though possibly technically challenging, it woud be interesting to replace the IRISs with non-repetitive DNA of similar size, thus preserving the overall endogenous structure. 
Another approach relied on insertion of l $\alpha$ promoter downstream of the $3^{\prime}$ RR (Braikia et al., 2017), thus preserving the integrity of the $3^{\prime} R R$ (Fig. 2). In this mouse line, duplication of I $\alpha$ affected GLT and CSR in a relatively complex manner (Santos et al., 2018). The ectopic l $\alpha$ promoter, but not the endogenous $\mid \alpha$, was already active in resting $B$ cells, and was further induced after activation, together with the endogenous l $\alpha$ (Braikia et al., 2017; Santos et al., 2018). The duplication had no effect on $S \gamma 3$ GLT and CSR to IgG3. GLT of $S \gamma 1$, S $\gamma 2 a$, and $S \varepsilon$, and CSR to IgG1, IgG2a and IgE were reduced. Surprisingly, S $\alpha$ GLT was unaffected but IgA CSR was reduced. Activation of S $\gamma 2 b$ GLT depended on the type of stimulation. LPS stimulation reduced S $\gamma 2 b$ GLT and IgG $2 b$. However, in the presence of TGF- $\beta$ (which also activates I $\alpha$ ), S $\gamma 2 b$ GLT and IgG2b CSR were unaffected (Santos et al., 2018). It may be of significance that S $\gamma 3$ GLT, the usual target of combined deletions in the $3^{\prime} R R$, was unaffected. Nonetheless here too, it is unclear if the active ectopic l $\alpha$ promoter exerted its effect by perturbing the 3D structure of the $3^{\prime} \mathrm{RR}$, by interfering with transcription elongation of sense and antisense transcription downstream of the $3^{\prime} R R$, or both.

Thus, at this point, the general picture that emerges is that the $3^{\prime} \mathrm{RR}$ as a whole is the master element in the control of GLT and CSR. The 3'RR controls CSR by regulating GLT of S sequences, but this correlation is not absolute, and overall, the $3^{\prime}$ RR has a moderate impact on GLT at $S \mu$ region. The $3^{\prime} R R$ enhancers display redundancy but act in synergy for efficient CSR. The global architecture of the $3^{\prime} R R$ appears to contribute to its full activity, and components of the $3^{\prime} R R$ may display some isotype preference (see below).

\subsubsection{The 3'RR and locus suicide recombination}

The seminal observation that the $3^{\prime} \mathrm{RR}$ was highly enriched in switch-like repeats (Chauveau and Cogné, 1996), and that it was transcribed upon induction of CSR (Péron et al., 2012) raised the possibility that the $3^{\prime}$ RR could be a substrate for a CSR-like process. However, unlike 
classical CSR, any recombination event involving $S \mu$ and the $3^{\prime} \mathrm{RR}$ will lead to the loss of the whole $C_{H}$ region, and part of or the whole 3'RR depending on the sites of DNA breaks (Péron et al., 2012). This phenomenon, termed locus suicide recombination (LSR), was first reported in mouse activated splenic B cells (Péron et al., 2012). Because LSR results in the loss of surface Ig expression required for B cell survival, it was suggested that LSR may be important for B effector cell differentiation and homeostasis, for instance by counter-selecting activated mature B cells with harmful Ig specificities (Péron et al. 2012).

Just like classical CSR, LSR was AID-dependent, and the 3'RR and flanking sequences bound AID in a pattern that closely mimicked that of RNA polymerase II (RNAp II) (Péron et al., 2012; Yamane et al., 2011), further connecting AID binding to induced 3'RR transcription. LSR reportedly occurred at levels approaching classical CSR as detected by PCR/Southern blot on excised episomal circles (Péron et al., 2012), though apparently not by more sensitive techniques (Meng et al., 2014; Qian et al., 2014). Recently, LSR was also detected at the human IgH locus undergoing CSR, suggesting conservation of the process between humans and mice (Dalloul et al., 2019). The human IgH locus contains two 3'RRs that include switch-like repeats: 3'RR1 downstream of C $\alpha 1$, and 3'RR2 downstream of C $\alpha 2$ (Mills et al., 1997, Pinaud et al., 1997) (Fig. 1B). LSR targeted the two 3'RRs, occurred at low frequency in healthy individuals, and was AID-dependent as judged by the absence of LSR in AID-deficient patients (Dalloul et al., 2019).

At this stage, it is still unclear if LSR is an autonomous process with potentially its specific mechanisms although it happens to co-occur and to share some features with classical CSR. The presumed bias of LSR towards the expressed allele (Dalloul et al., 2019) may point to specific mechanisms. Alternatively, LSR may be a byproduct of classical CSR. For instance LSR could result from an accidental attack of the transcribed $3^{\prime} R R$ by AID. It should be acknowledged that depressed B cells about to commit suicide or that rapidly disappear from 
switched B cell pools are hardly a comfortable system for detailed studies. Nonetheless, it should be possible to engineer mouse models and exploit existing ones to further explore the mechanisms underlying LSR and its biological significance.

\subsubsection{The $\mathbf{3}^{\prime} \mathrm{RR}$ and class switch recombination to $\lg \mathrm{D}$}

$\operatorname{lgD}$ is co-expressed with IgM on the surface of normal naïve mature $B$ cells. Expression of the $C \delta$ gene results essentially from alternative splicing of a long primary transcript encompassing $C \mu$ and $C \delta$ exons (Chen and Cerutti 2010; Preud'homme et al. 2000). CSR to IgD is generally considered as a rare event and has been mostly studied in humans where B cells that switch to $\lg \mathrm{D}$ are relatively abundant in the upper aerodigestive mucosa-associated lymphoid tissues (Chen and Cerutti 2010). In contrast to other isotypes, $C \delta$ gene has no canonical switch sequence, although a G-rich pentameric, switch-like sequence called $\sigma \delta$, is present upstream of $\mathrm{C} \delta$ exons, and was involved in recombination events with $\mathrm{S} \mu$ (Arpin et al., 1998; Gilliam et al., 1984; Kluin et al., 1995; White et al., 1990; Yasui et al., 1989. Reviewed in Chen and Cerutti, 2010; Preud'homme et al., 2000). The transcriptional mechanisms that underlie CSR to IgD are still poorly understood. Although CSR to $\operatorname{IgD}$ is rare in the mouse and is not detectable in splenic B cells (the classical model in CSR studies), the major breakthrough actually came from an analysis of CSR to IgD in mouse mesenteric lymph nodes (Rouaud et al., 2014). This study revealed that, while AID-dependent, CSR to IgD was 3'RR-independent, and was even increased in the absence of the $3^{\prime} R R$ (Rouaud et al., 2014).

This raises the question as to the nature of the transcriptional elements that are involved in the control of CSR to IgD. The primary candidate may be the proximal E $\mu$ enhancer. Another candidate could be a region lying downstream of $C \delta$ gene, that is highly enriched in transcription factors binding sites (Mundt et al., 2001), and whose function is still unknown. 


\subsubsection{The $3^{\prime} R R$ and class switch recombination in B1 B-cells}

Most if not all of our knowledge on the role of the $\mathrm{IgH}$ regulatory elements in CSR is based on the use of B2 B-cells, the major B-cell population in the spleen. Regardless of the ongoing debate on their origin, B1 B cells are the main B-cell population in the pleural and peritoneal cavities, and display distinct antigen specificity and cell surface markers, and a CSR bias to IgA (Ehrenstein and Notley, 2010; Tung and Herzenberg, 2007). Whether IgH regulatory elements control CSR through the same mechanisms in B1 and B2 B-cells has not been investigated in detail. Recently, it was found that, in contrast to B2 B-cells, CSR to IgA in B1 B-cells was 3'RRindependent (Issaoui et al., 2018). When B1 B-cells of the peritoneal cavity were stimulated in vitro, surface expression of IgA was comparable between 3'RR-deficient B1 B-cells and wild type controls. However, IgA titers in culture supernatants of activated mutant B1 B-cells were markedly reduced, and the reduction was associated with decreaed levels of $I \mu-C \alpha$ postswitch transcripts (Issaoui et al., 2018), but it is unclear if S $\alpha$ GLT was affected in activated B1 B-cells. Notwithstanding, it was suggested that, in contrast to B2 B-cells, CSR to IgA in B1 Bcells was $3^{\prime}$ RR-independent. However, the $3^{\prime}$ RR was required for efficient transcription of the switched C $\alpha$ gene (Issaoui et al., 2018).

This finding raises intriguing questions on the transcriptional mechanisms involved in B1 Bcells, in particular on the interplay between cytokine requirements and the cis-acting elements involved. Additionally, the distinct roles of the $3^{\prime} \mathrm{RR}$ in B1 and B2 B-cell populations appear to extend to other processes. Thus, while the $3^{\prime}$ RR deletion impacted late repertoire diversity in B1 B-cells, it did not in B2 B-cells (Ghazzaui et al., 2017). Further investigations are required to unravel the mechanisms underlying the function of the $3^{\prime} R R$ in $B 1$ B-cells. 


\subsection{The $3^{\prime} \gamma 1 E$ enhancer}

Extensive 4C-seq analyses identified two sites located between $C \gamma 1$ and $C \gamma 2 b$ genes, that interacted in particular with E $\mu$ enhancer, the 3'RR and the $3^{\prime} \mathrm{CBEs}$ in Rag2-deficient pro-B cells (Medvedovic et al., 2013). These interaction sites (hereafter $3^{\prime} \gamma 1 \mathrm{E}$ and 5'l $\gamma 2 \mathrm{~b}$ ) bind IRF4, IRF8, PU1, E2A, YY1, and PAX5 transcription factors, and contain PAX5-dependent hss (Medvedovic et al., 2013). The $3^{\prime} \gamma 1 \mathrm{E}$ also binds the MED1 subunit of Mediator complex in developing cells (Predeus et al., 2014 ; Whyte et al., 2013), and displays enhancer activity in pro-B cells (Predeus et al., 2014). While the potential involvement of the $5^{\prime} \mid \gamma 2 b$ element in CSR has not been established yet, the role of the $3^{\prime} \gamma 1 \mathrm{E}$ has recently been investigated (Amoretti-Villa et al., 2019). Through 4C-seq experiments, it was found that the $3^{\prime} \gamma 1 \mathrm{E}$ interacts with E $\mu$ enhancer and the $3^{\prime}$ RR during CSR. Additionally, the $3^{\prime} \gamma 1 E$ element binds MED1 and MED12 subunits of Mediator complex (Thomas-Claudepierre et al., 2016), and is transcribed in activated B cells (Thomas-Claudepierre et al., 2016). Deletion of this element in the CH12F3 cell line (hereafter $\mathrm{CH} 12$ line) reduced by about half the efficiency of CSR to IgA. Surprisingly, the defective switching occurred despite normal levels of S $\alpha$ transcript levels (Amoretti-Villa et al., 2019). The reasons underlying the lack of correlation between IgA CSR and normal S $\alpha$ GLT are unclear, and may relate to the relative proximity of $S \alpha$ to the $3^{\prime} R R$, but could also reflect particular features of the $\mathrm{CH} 12$ line (Amoretti-Villa et al., 2019) (see section 3). Interestingly, in the corresponding mouse model, activated 3' $\gamma 1 \mathrm{E}$-deficient B cells displayed reduced CSR to $\operatorname{lgG} 3$, IgG2b, and IgG2a, which correlated with defective GLT across $5 \gamma 3,5 \gamma 2 b$ and $5 \gamma 2 a$ (Amoretti-Villa et al., 2019) (Fig. 2). Thus, the 3' $\gamma 1$ E emerges as a transcriptional enhancer that regulates CSR in an isotype-specific manner, although a role for the $3^{\prime} \gamma 1 \mathrm{E}$ in the architecture of the IgH $\mathrm{C}_{H}$ locus was not excluded (Amoretti-Villa et al., 2019). 


\subsection{CTCF binding elements}

For decades, intense efforts focused on the role of promoters and enhancers and bound transcriptional/architectural factors in the control of the lineage- and the developmental stage-dependent expression of the IgH locus (Atchison, 2014; Birshtein, 2014; Cobaleda et al. 2007; Khamlichi et al., 2000; Kumari and Sen, 2015; Perlot and Alt, 2008; Pinaud et al., 2011). Identification of CTCF binding elements (CBEs) at the $\mathrm{IgH}$ locus provided additional layers of regulation, and consequently a more complex picture of the mechanisms that control $\mathrm{g} g \mathrm{H}$ locus expression.

CTCF was involved in transcriptional regulation, insulator activity, and chromatin boundary formation (e.g. Bell et al., 1999; Sexton et al., 2012. Reviewed in Ong and Corces, 2014), though long-range interactions are not always prevented by CTCF binding, and CBEs do not necessarily demarcate insulated chromatin domains (Sanyal et al., 2012).

Multiple CBEs were identified along the $\mathrm{IgH}$ locus, the majority of which lie within the variable domain, and two CBEs with insultor function were identified within the $\mathrm{V}_{\mathrm{H}}$ - $\mathrm{D}$ intergenic region (Degner et al., 2009; Degner et al., 2011; Featherstone et al., 2010; Guo et al., 2011). A large cluster of CBEs was identified downstream of the 3'RR (Garrett et al., 2005), and more recently, a CBE was identified within the $C \alpha$ gene (Thomas-Claudepierre et al., 2013). The role of CTCF in chromatin loops formation during CSR will be discussed later. Here, we will only describe the effect of ablation of Ctcf gene or CBEs on GLT and CSR.

\subsubsection{The 3'CTCF binding elements}

Multiple hs elements, initially termed hs5, hs6, and hs7, were identified downstream of hs4 enhancer (Garrett et al., 2005), which displayed active chromatin marks at the pro-B cell stage already. The hs5-7 region is highly enriched in CBEs, and its hs elements exhibit insulator 
activity in vitro (Garrett et al., 2005). Deletion of the majority of CBEs had no effect on CSR to all isotypes tested except a modest but potentially significant increase of CSR to IgG1 (Volpi et al., 2012) (Fig. 2). By chromosome conformation capture (3C) assay, the deletion had no apparent effect on the crosslinking frequency between the components of the $3^{\prime} R R$, of the 3'RR with $\mathrm{E} \mu$, or of the 3'RR with I promoter regions. It should be noted that the hs5-7 deletion did not encompass all the $3^{\prime}$ CBEs, and the remaining CBEs may explain the phenotype, for instance why no loops were detected in activated B cells between hs3a and the Hole gene, the nearest known downstream gene. It will be interesting to delete the whole cluster in order to clarify the role of the $3^{\prime} \mathrm{CBEs}$ in CSR and the $3 \mathrm{D}$ architecture of the $\mathrm{IgH}$ locus.

\subsubsection{The 5'hs1RI insulator}

With regard to the control of GLT, the notion that prevailed was that the $3^{\prime}$ RR-mediated activation of I promoters was restricted to activated mature B cells. It was not therefore clear if I promoters were inherently transcriptionally inactive before B cell activation or if they were transcriptionally competent but were silent because of some insulation from the $3^{\prime} R R$. In the latter case, this would imply that the $3^{\prime} \mathrm{RR}$ has the potential to activate I promoters even before activation of mature B cells. A likely candidate for such insulator function was an hs located in the last intron of the $C \alpha$ gene (Kakkis et al., 1988). Besides its strategic position between the $3^{\prime} R R$ and upstream I promoters, this element displayed an intereresting feature: it bound CTCF and Cohesin prior to B cell stimulation (Thomas-Claudepierre et al., 2013), but evicted CTCF though not Cohesin upon activation (Braikia et al., 2017; Thomas-Claudepierre et al., 2013). This element termed $5^{\prime} \mathrm{hs} 1 \mathrm{RI}$, is conserved in the human $C \alpha 1$ and $C \alpha 2$ genes (Braikia et al., 2017). 
The function of this CBE was investigated by genetic ablation of the C $\alpha 3-\mathrm{C} \alpha \mathrm{mb}$ intervening sequence encompassing the hs and the CBE in the germline. Strikingly, S $\gamma 3$ transcripts and, to a lesser extent $S \gamma 2 b$ and $S \gamma 2 a$ transcripts, were markedly up-regulated in unstimulated 5'hs1RI-deficient splenic B cells. No such up-regulation was detected for $S \gamma 1$, S $\varepsilon$, and $S \alpha$ GLT (Braikia et al., 2017). The 5'hs1RI element contributed to the regulation of CSR in a relatively complex way. Thus, increased CSR to IgG2b correlated with increased S $\gamma 2 b$ GLT. However, CSR to IgG3 was defective despite seemingly abundant $\mathrm{S} \gamma 3 \mathrm{GLT}$. Whether this is due to promoter interference incurred by the downstream, potentially more active $1 \gamma 2 \mathrm{~b}$ promoter, or to other mechanisms remains to be investigated (see section 5.1). Notwithstanding, the $5^{\prime}$ hs1RI emerges as a cis-acting regulatory element that acts, at least in part, as an inducible CTCF insulator, whose function is to block premature activation of $1 \gamma 3,1 \gamma 2 b$ and $1 \gamma 2 \mathrm{a}$ promoters before B-cell activation, strongly suggesting that $5^{\prime}$ hs1RI is somehow involved in the transcriptional silencing of these promoters. In contrast, GLT of $S \gamma 1, \mathrm{~S} \varepsilon$ and $\mathrm{S} \alpha$ is $5^{\prime} \mathrm{hs} 1 \mathrm{RI}-$ independent.

How transcriptional silencing is achieved is presently unclear, but may involve an interaction between the $5^{\prime} \mathrm{hs} 1 \mathrm{RI}$ and the $3^{\prime} \mathrm{CBEs}$ downstream of the $3^{\prime} \mathrm{RR}$, which would insulate the $3^{\prime} \mathrm{RR}$ from upstream I promoters before B-cell activation (Fig. 4). It should be noted that 5'hs1RI deletion and $3^{\prime} \gamma 1 \mathrm{E}$ deletion affect the same I promoters, i.e. $1 \gamma 3,1 \gamma 2 \mathrm{~b}$ and $1 \gamma 2 \mathrm{a}$. Whether this convergence involves long-range interactions between $5^{\prime} \mathrm{hs} 1 \mathrm{RI}$ and $3^{\prime} \gamma 1 \mathrm{E}$ is presently unknown.

The role of CTCF in CSR was investigated by using a conditional knock-out of Ctcf gene that enabled CTCF depletion in naïve B cells (Marina-Zárate et al., 2017). Intriguingly, CTCF depletion led to increased transcript levels of the switch isotypes tested, $S \gamma 3, S \gamma 2 b$ and $S \gamma 1$, in unstimulated B cells, strongly suggesting that CTCF plays an important role in blocking switch transcription until B cells get activated (Marina-Zárate et al., 2017). 
Taking into account the two studies (Braikia et al., 2017; Marina-Zárate et al., 2017), it is tempting to speculate that inhibition of premature $S \gamma 3$ and $S \gamma 2 b$ GLT is CTCF-dependent and involves, at least in part, $5^{\prime}$ hs $1 \mathrm{RI}$, while inhibition of premature $\mathrm{S} \gamma 1$ transcription is CTCFdependent but $5^{\prime}$ hs1RI-independent. Further investigations are required to dissect the precise mechanisms involving CTCF in the control of GLT and CSR to each isotype.

\section{Class switch recombination in the $\mathrm{CH} 12 \mathrm{~F} 3$ cell line}

At this point, it may be of interest to briefly discuss the discrepancies between the phenotypes of some IgH enhancer knock-outs in $\mathrm{CH} 12$ cells and primary B cells.

The contrast between the effect of $3^{\prime} \gamma 1 \mathrm{E}$ deletion in $\mathrm{CH} 12$ cells (reduced IgA CSR despite normal S $\alpha$ GLT) and in primary B cells (normal S $\alpha$ GLT and IgA CSR) (Amoretti-Villa et al., 2019) has already been mentioned in section 2.4.

Deletion of the whole 3'RR in the $\mathrm{CH} 12$ line reduced but did not abolish CSR to IgA (Kim et al., 2016). Interestingly, 3’RR deletion suppressed $\mathrm{S} \alpha \mathrm{GLT}$ in unstimulated $\mathrm{CH} 12$ cells. However, upon stimulation with anti-CD40+IL4+TGF- $\beta$, S $\alpha$ GLT was only slightly affected (Kim et al., 2016) (Fig. 2 and associated table). This contrasts with the strong defect of S $\alpha$ GLT and IgA CSR seen in 3'RR-deficient splenic B cells (Vincent-Faber et al., 2010), though may be not with primary B1 B-cells (Issaoui et al., 2018) (see section 2.3.3).

The milder effect of $3^{\prime} \mathrm{RR}$ deletion in $\mathrm{CH} 12$ cells suggested that, although capable of enhancing CSR, the $3^{\prime}$ RR was not absolutely required for targeting of AID to S regions or CSR per se (Kim et al., 2016). When the whole $3^{\prime}$ RR was replaced with the its four enhancers, CSR to IgA was restored to wild type levels and was even increased in some $\mathrm{CH} 12$ clones (Kim et al., 2016). This was interpreted as an indication that most of the $3^{\prime}$ RR-mediated control of CSR was confined within the hss, though the potential presence of inhibitory elements within the palindrome, that may account for the increased level, was not excluded (Kim et al., 2016). The 
phenotype of core $3^{\prime} \mathrm{RR}$ in $\mathrm{CH} 12$ cells also contrasts with core $3^{\prime} \mathrm{RR}$ splenic B cells, the latters displaying a moderate reduction of GLT and CSR (Lenoir et al., 2017) (see section 2.3).

The $\mathrm{CH} 12$ line was derived from a mouse $\mathrm{B}$ cell lymphoma and represents a mature stage of the B1 cell lineage (Haughton et al., 1986; Ono et al., 2000; Nakamura et al., 1996). CH12 line switches exclusively to IgA and is known to produce abundant levels of S $\alpha$ GLT even before activation (Nakamura et al., 1996).

A potential caveat with knock-out studies of $\mathrm{IgH}$ enhancers in $\mathrm{CH} 12$ line is that $\mathrm{CH} 12$ is a preactivated line that has already undergone $\mathrm{S} \mu / \mathrm{S} \alpha$ on the non-expressed allele (Ono et al., 2000 ; Kim et al., 2016 ; Santos et al., 2019b), thus its 3'RR is active even before stimulation (Kim et al., 2016 ; Santos et al., 2019b), and its own transcriptional activity does not vary after standard anti-CD40+IL4+TGF- $\beta$ stimulation (Santos et al., 2019b; Zhang et al., 2019a). In this regard, it should be noted that the $\mathrm{CH} 12$ line displays a bias towards TGF- $\beta$ stimulation signals (Santos et al., 2019b) whose potential impact on $3^{\prime}$ RR activity is yet to be investigated. Additionally, though not known at the time of the above studies, the transcriptional landscape downstream of the $\mathrm{IgH} \mathrm{C}_{\mathrm{H}}$ region in $\mathrm{CH} 12$ cells differs from that of primary B cells (Zhang et al., 2019a), and it is still unclear to what extent this difference may explain the above discrepancies.

It was suggested that the phenotypic differences between $\mathrm{CH} 12$ cells and primary B cells may stem from the apparent 3'RR-independent CSR to IgA in B1 cells (Issaoui et al., 2018, AmorettiVilla et al., 2019). The comparison should however be toned down by the fact that CSR to IgA in $\mathrm{B} 1$ cells was assayed on presumably resting $\mathrm{B} 1$ cells of the peritoneal cavity whereas $\mathrm{CH} 12$ cells have already experienced activation and switching.

Finally, it is unknown if the lymphoma origin of $\mathrm{CH} 12$ cells has anything to do with its preactivated state, for instance by affecting signaling pathways and transcription regulatory circuits. 
Keeping these potential caveats in mind, the fact remains that the $\mathrm{CH} 12$ line, with its capacity to switch with a very high frequency, provides the investigators with a valuable tool to dissect various mechanistic aspects of CSR (e.g. Kim et al., 2016; Ribeiro de Almeida et al., 2018; Zhang et al., 2015; Zheng et al., 2015; Zhang et al., 2019a).

\section{Class switch recombination in developing B cells}

CSR can occur in developing B cells, albeit at lower frequency in comparison to mature B cells. Seminal studies detected CSR in Abelson murine leukemia virus (A-MuLV)-transformed pro-B lines (e.g. Akira et al., 1983; Alt et al., 1982; Burrows et al., 1983; Kubagawa et al., 1983; Sugiyama et al., 1986), and subsequent studies showed that CSR could occur in early primary B cells (e.g. Edry et al., 2007; Edry et al., 2008; Han et al., 2007; Hasan et al., 2002; Kumar et al., 2013; Seagal et al., 2003). In contrast to mature B cells, the signaling pathways and the transcriptional regulatory elements that control CSR in developing B cells are less known. Two lines of investigations brought some insights into the signaling pathways and the regulatory elements involved.

Thus, there is evidence that signaling through Toll-like receptors can induce AID expression and CSR at early developmental stages (e.g. Edry et al., 2008; Han et al., 2007; Swaminathan et al., 2015). Recently, IL7, a non-redundant cytokine that plays an important role in early B and T cell development (Ceredig and Rolink, 2012; Clark et al., 2014; Corfe and Paige et al., 2012, Hosokawa and Rothenberg, 2018) was implicated in the control of GLT in cultured primary pro-B cells (Dauba et al., 2020). By using a stromal cell-free culture system that highly enriches in primary pro-B cells, IL7 was found to repress $1 \gamma 3$ and, to a lesser extent, $1 \gamma 2 b$ promoter in propagated pro-B cells. No such effect was observed in propagated Rag2deficient pro-B cells, suggesting that IL7 exerted its inhibitory effect on pro-B cells that underwent V(D)J recombination (Dauba et al., 2020). Nonetheless, silencing of $1 \gamma 3$ and $l \gamma 2 b$ 
promoters was suppressed upon stimulation with LPS, which induced S $\gamma 3$ and S $\gamma 2 b$ GLT and CSR to $S \gamma 3$ and $S \gamma 2 b$ respectively, with a stronger and faster effect on I $\gamma 3$ promoter (Dauba et al., 2020). Induction of GLT was not restricted to $S \gamma 3$ and $S \gamma 2 b$, as $S \gamma 1$ and $S \varepsilon$ transcript levels, which were undetectable in cultured unstimulated pro-B cells, were increased upon LPS+IL4 stimulation (Dauba et al., 2020). However, the mechanism by which IL7 inhibits GLT remains to be explored.

Another line of evidence involves 5'hs1RI (Braikia et al., 2017). In the absence of this element, relatively high levels of $S \gamma 3$ and, to a lesser extent, $S \gamma 2 b$ transcripts were readily detected in unstimulated pro-B and pre-B cells (Braikia et al., 2017). The increase of $S \gamma 3$ and $S \gamma 2 b$ transcript levels occurred in the absence of detectable 3'RR eRNAs (Braikia et al., 2017), suggesting that $3^{\prime} R R$ eRNAs were not required for the constitutive activity of the $3^{\prime} R R$ at the pro-B cell stage. Accordingly, duplication of I $\alpha$ promoter downstream of the $3^{\prime} R R$ led to a premature activation of the ectopic, but not the endogenous, $I \alpha$ at the pro-B cell stage. Notwithstanding, the data with 5 'hs1RI deletion and I $\alpha$ duplication suggest that the $3^{\prime} \mathrm{RR}$ exhibits a constitutive enhancer activity and that it has the potential to activate upstream I promoters of the $\mathrm{IgH}$ constant domain before antigenic induction (Braikia et al., 2017). It may be of significance that the primary target of 5'hs1RI and IL7 in non-activated pro-B cells is $1 \gamma 3$ promoter and, to a lesser extent, $1 \gamma 2 \mathrm{~b}$. The reasons underlying the preferential targeting of $I \gamma 3$ are still unknown, and suggest that $l \gamma 3$ promoter is subject to relatively specific control mechanisms (Braikia et al., 2017; Oudinet et al., 2019).

Though mechanistic studies are still needed, the above findings strongly suggest that active mechanisms operate in developing B cells to down-regulate GLT and CSR, and that IL7/IL7R pathway(s) and 5'hs1RI element are part of these mechanisms (Dauba et al., 2020).

Other aspects on the mechanism of CSR in pro-B lines will be discussed in section 5.4. 


\section{Mechanism and regulation of class switch recombination}

\subsection{Competition versus co-regulation}

Stimulation of primary B cells often activate more than one I promoter raising the question as to whether activated promoters compete for the $3^{\prime} \mathrm{RR}$ or whether they are co-activated. Previous mutational studies on B cell populations concluded that I promoters compete for 3'RR activity (e.g. Braikia et al., 2017; Cogné et al., 1994; Manis et al., 1998; Oruc et al., 2007; Seidl et al., 1999). However, it remained uncertain whether I promoters located on the same chromosome and that respond to the same stimulus compete for $3^{\prime} R R$ activity. The issue is complicated by the fact that GLT can occur on both alleles (Casola et al., 2006; Delpy et al., 2003; Wu et al., 2017). The use of mouse models with a transcriptionally dead or constitutively transcribed allele as well as polymorphic allelic differences, and the design of a singlechromosome RT-qPCR assay enabled to track, on a monoallelic basis, I promoter activation by the $3^{\prime} R R$ in the endogenous context (Santos et al., 2019a). The analyses revealed two modes of cis-activation, competition and co-activation, depending on the type of stimulation (Santos et al. 2019a). Thus, in the presence of IL4 or TGF- $\beta$, the majority of alleles displayed promoter competition, though the patterns were different. While S $\gamma 1$-single expressers prevailed over SE-single-expressers (Santos et al., 2019a; Wu et al., 2017), there were similar percentages of single S $\gamma 2 b$ - and S $\alpha$-expressing alleles (Santos et al., 2019a). However, upon LPS stimulation, the $3^{\prime}$ RR co-activated $I \gamma 3$ and $l \gamma 2 b$ promoters. Moroever, $\mid \gamma 2 b$ promoter was often activated on alleles that had previously activated $I \gamma 3$.

The lack of significant competition between activated $1 \gamma 3$ and $1 \gamma 2 \mathrm{~b}$ promoters suggests that 3'RR activity, RNAp II, and transcription factors are not limiting, and that initial activation of one promoter does not exclude activation of the other (Santos et al., 2019a). The high percentage of co-transcribing alleles and the comparable half-lives of $5 \gamma 3$ and $S \gamma 2 b \mathrm{GL}$ 
transcripts make unlikely the hypothesis of a non-synchronized activation that would invlove a fast shift of the $3^{\prime} R R$ from one promoter to the other. In this regard, the case of $I \gamma 2 b$ promoter, which responds to both LPS and TGF- $\beta$ is highly significant: $1 \gamma 2 \mathrm{~b}$ was almost always co-activated with $1 \gamma 3$ after LPS stimulation, and almost never co-activated with l $\alpha$ upon TGF$\beta$ stimulation (Santos et al., 2019a). Thus, the notion that emerges is that the the type of activation signal received by the B cell is important in determining which mode of activation of I promoters, co-activation or competition, will prevail.

The single-chromosome approach also allowed to solve the issue of the polarity of the $3^{\prime} \mathrm{RR}$, i.e. if the $3^{\prime} R R$ activity was exclusively oriented towards the upstream I promoters or if it could also target a downstream promoter. Implicit to this question is whether I promoters that flank the $3^{\prime}$ RR compete for its activity or whether they can be co-activated. In the mouse model with an la promoter inserted downstream of the 3'RR (Braikia et al., 2017) (Fig. 2), activation of the downstream l $\alpha$ promoter started in pro-B cells and the promoter remained active until resting the mature B cell stage, while the endogenous I $\alpha$ was silent (Braikia et al., 2017). Upon stimulation, both the endogenous and the ectopic l $\alpha$ promoters were activated in B cell populations (Braikia et al., 2017; Santos et al., 2018). Analysis at the single-chromosome level revealed that, in its endogenous setting, the $3^{\prime} R R$ activated both promoters, pointing to a bidirectional activity (Santos et al., 2018).

That two promoters can be co-activated by a shared enhancer is not without precedents. In keeping with a classical comparison, the $\beta$-globin locus, a recent study showed that, in their endogenous context, two distant but developmentally synchronized promoters were coactivated by the $\beta$-globin super-enhancer with no interference from previously activated proximal promoters (Allahyar et al., 2018). On the other hand, the $3^{\prime}$ RR long-range activates the translocated c-Myc oncogene (Gostissa et al., 2009), which can accompany CSR to activated downstream S regions (Janz, 2006). This implies co-activation of the translocated c- 
Myc as well as the promoter of the target S region on the same chromosome. The co-activating capacity of the $3^{\prime} \mathrm{RR}$ likely facilitates this process (Santos et al., 2019a). Lastly, in the context of transcriptional bursting, there is evidence in Drosophila that two distant promoters can be simultaneously activated by a shared enhancer in coordinated transcriptional bursts, suggesting that co-activation and bursting are not mutually exclusive processes (Fukaya et al., 2016).

It is now admitted that transcription is episodic, consisting of a series of discontinuous bursts. Different developmental enhancers produce transcriptional bursts with similar amplitudes and duration but generate very different bursting frequencies, with strong enhancers producing more bursts than weak enhancers (Fukaya et al., 2016. Reviewed in Furlong and Levine, 2018; Hnisz et al., 2017; Rodriguez and Larson, 2020). In this regard, It will be interesting to determine the transcriptional burst of the $3^{\prime} R R$ and its interplay with signaling and the mode of activation of I promoters.

\subsection{Transcriptional and epigenetic regulation by the 3' Regulatory Region}

Two aspects of epigenetic regulation of GLT will be reviewed in this section. One concerns the epigenetic modifications at the $3^{\prime} R R$ itself, and one relates to epigenetic modifications at target I promoters. We focus mainly on recent work on the control of histone modifications and DNA methylation at I promoter regions by the $3^{\prime}$ RR. Earlier studies on important aspects of epigenetic regulation of AID targeting and CSR have been reviewed (Birshtein, 2014; Daniel and Nussenzweig, 2013; Kenter, 2012; Stavenezer et al., 2008), and will be mentioned here only when pertinent.

With respect to the $3^{\prime} R R$ and $3^{\prime} C B E s$, previous studies, using chromatin immunoprecipitation (ChIP) and methylation-sensitive restriction enzymes, revealed a characteristic general pattern. Active epigenetic marks were acquired in a sequential and polarized manner, from 
the 3'CBEs towards the 3'RR palindromic enhancers, hs3a, hs1,2 and hs3b (Garrett et al., 2005; Giambra et al., 2008. Reviewed in Birshtein, 2014). Broadly outlined, histone H4 acetylation (H4Ac) and, to a lesser extent, $\mathrm{H} 3 \mathrm{Ac}$ were already acquired by the $3^{\prime} \mathrm{CBEs}$ in pro-B cells, and $3^{\prime} \mathrm{CBEs}$ and hs4 enhancer were demethylated. At the pre-B cell stage, both histone marks were to various levels enriched at hs4 enhancer, and in mature B cells, hs $3 a$, hs1,2, and hs3b enhancers acquired both epigenetic modifications, active histone marks and DNA demethylation (Garrett et al., 2005; Giambra et al., 2008. Reviewed in Birshtein, 2014).

By using bisulphite sequencing to analyze the methylation profiles of various cis-acting elements at the $\mathrm{IgH} \mathrm{C}_{\mathrm{H}}$ locus, it was found that the methylation patterns of most cis-acting elements were established and faithfully maintained independently of B cell activation or GLT (Oudinet et al., 2019). Except for I $\gamma 1$ whose demethylation was induced, induction of GLT did not perturb the methylation patterns of I promoters. For instance, $1 \gamma 3$ and $1 \gamma 2 \mathrm{~b}$ promoters were already unmethylated in resting splenic B cells and remained so after LPS activation, whereas the hypermethylated pattern of I $\varepsilon$ remained unchanged upon activation (Oudinet et al., 2019). Similarly, the unmethylated pattern of $E \mu$ and $3^{\prime} \gamma 1 E$ did not vary upon $B$ cell activation or insulation of the 3'RR (Oudinet et al., 2019). Thus, methylation profiles of the $C_{H}$ locus elements analyzed were essentially transcription-independent. Importantly, the unmethylated pattern of $|\gamma 3,| \gamma 2 b$ and $3^{\prime} \gamma 1 E$ did not change upon insulation or deletion of the 3'RR, which fully repressed $I \gamma 3$ and $1 \gamma 2 b$ promoters (Oudinet et al., 2019, and unpublished observations). This implies that the long-range interactions between the $3^{\prime} R R$ and these promoters (Amoretti-Villa et al., 2019; Sellars et al., 2009; Thomas-Claudepierre et al., 2013; Thomas-Claudepierre et al., 2016; Wuerffel et al., 2007) (see section 5.3) neither require nor induce their demethylation (Oudinet et al., 2019).

Various studies on mammalian inducible genes showed that recruitment of RNAp II transcription machinery to a promoter is a key step in the initiation of transcription (Weake 
and Workman, 2010). An additional mechanism used to achieve efficient and timely transcription is the pausing of RNAp II shortly after initiation, a critical step in the regulation of transcription elongation (Core and Adelman, 2019). With respect to pausing of RNAp II during GLT, one needs to consider two aspects: one relates to the "classical" pausing at the transition initiation/elongation. The second aspect is more specific and relates to events associated with transcription elongation across $\mathrm{S}$ regions. In particular, transcribed $\mathrm{S}$ regions show a marked stalling of RNAp II at S sequences (Rajagopal et al., 2009; Wang et al., 2009), and an extended zone of chromatin activating modifications (Daniel et al., 2010; Wang et al., 2006; Wang et al. 2009).

In this regard, induction of GLT was shown to be associated with various active histone modifications (Daniel and Nussenzweig, 2013; Kenter, 2012). The general pattern of histone modifications during initiation and elongation of induced GLT was similar to transcription activation of non-lg genes. Nonetheless, there were interesting exceptions whose significance and interplay with the activity of $I g H$ transcriptional elements are still unclear. Notably, histone acetylation and $\mathrm{H} 3 \mathrm{~K} 4 \mathrm{me} 3$ mark were not confined to the transcriptional start siteflanking region as is generally the case with active genes, but extended over the entire $\mathrm{S}$ regions regardless of their length (up to $10 \mathrm{~kb}$ for $S \gamma 1$ ), and dropped at $C_{H}$ exons (Daniel et al., 2010; Wang et al., 2009). In correlation with the constitutive transcription of S $\mu$ region, these patterns were found in $S \mu$ in resting B cells and remained unchanged upon induction of GLT. In contrast, they were induced in downstream S regions (Daniel et al., 2010; Wang et al., 2009). How do S regions determine this pattern and whether they contain cryptic promoters (Haddad et al., 2011; Kenter, 2012) that might be regulated by the $3^{\prime} R R$ is still unknown. Notwithstanding, the finding that the chromatin profile of transcribed $\mathrm{S}$ regions remains unchanged in AID-deficient B cells indicates that it is specifically linked to GLT rather than to DNA break generation and/or repair (Daniel et al., 2010 ; Wang et al., 2009). 
Accumulating evidence suggests that GLT-asssociated H3K4me3 mark could direct the chromatin pattern of at least a subset of S regions. PTIP (PAX interaction with transcription activation domain protein) is a component of the mixed-lineage leukemia 3 (MLL3)/MLL4 complex, which catalyzes methylation marks on H3K4 (Daniel and Nussenzweig, 2013). Interestingly, PTIP-deficient B cells displayed a defect in GLT of $S \gamma 3, S \gamma 1, S \gamma 2 b$ and CSR to IgG3,

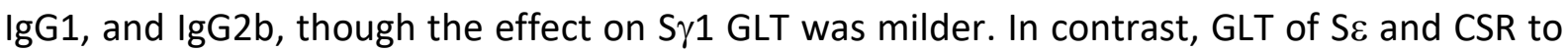
IgE were unaffected (Callen et al., 2013; Daniel et al., 2010; Schwab et al., 2011). Accordingly, ChIP-seq analyses revealed that activated PTIP-deficient B cells displayed impaired transcription initiation and reduced $\mathrm{H} 3 \mathrm{~K} 4 \mathrm{me} 2 / 3$ (but not $\mathrm{H} 3 \mathrm{~K} 4 \mathrm{me} 1$ ) and histone acetylation at activated S $\gamma 3$, S $\gamma 1$, and S $\gamma 2 b$ (Daniel et al., 2010 ; Schwab et al., 2011), suggesting that the reduced histone acetylation is likely a consequence of defective H3K4me2/3 deposition, and that a hierachy of histone modifications was involved in the control of GLT (Daniel et al., 2010). The precise mechanism by which PTIP promotes GLT at I promoters remains unclear but appears to be independent from its association with the MLL3/MLL4 complex (Daniel et al., 2010; Starnes et al., 2016).

Interestingly, the chromatin profiles of $\mathrm{S} \mu$ region and the $3^{\prime} \mathrm{RR}$ were unaffected in activated PTIP-deficient B cells (Daniel et al., 2010), though a relative decrease of H3K4me3 was reported for hs4 enhancer (Schwab et al., 2011), and there is some evidence that PTIP may be involved in long-range interactions between the $3^{\prime} R R$ and its target I promoters, possibly by stabilizing PAX5 binding to hs4. In activated PTIP-deficient B cells, these long-range chromatin interactions are disrupted (Schwab et al., 2011). Thus, it is plausible that besides its local effect on a subset of I promoters, PTIP may act, at least in part, as a bridge to connect the $3^{\prime}$ RR to these I promoters. Whether the long-range activity of PTIP is absolutely required to its local activity as a recruiter of histone methyltransferase is presently unclear. 
The transcriptional and epigenetic control of GLT by the 3'RR was investigated in mice devoid of the 3'RR. Activated 3'RR-deficient B cells displayed a dramatic decrease of Ser5-CTD RNAp II, associated with transcription initiation, and Ser2-CTD RNAp II, associated with elongation, along the downstream Ix-Sx-Cx regions. In contrast, 3'RR-deficiency only minimally affected RNAp II recruitment along I $\mu-S \mu-C \mu$ region (Saintamand et al., 2016). This suggests that GLT of acceptor S regions heavily depends on the $3^{\prime} \mathrm{RR}$ which controls their transcription initiation. With regard to histone modifications, 3'RR-deficiency reduced $\mathrm{H} 3 \mathrm{AC}$ and H3K4me3 marks deposition along the downstream $S$ regions, while $I \mu-S \mu-C \mu$ was essentially unaffected (Saintamand et al., 2016). Unexpectedly, H4Ac was not impaired in activated 3'RR-deficient or 3'RR-insulated B cells (Saintamand et al., 2016; Braikia et al., in preparation). This, together with the finding that control of I promoters by the $3^{\prime}$ RR does not involve their DNA methylation (Oudinet et al., 2019) raises the intriguing possibility that the $3^{\prime} R R$ controls GLT of acceptor $S$ regions through a specific epigenetic code.

Recently, the zinc finger MYND-type containing 8 (ZMYND8) protein, a histone mark reader that associates with promoters and enhancers in various cell types and can mediate transcriptional activation or repression, was identified as an important regulator of the $3^{\prime} R R$ transcriptional activity (Delgado-Benito et al., 2018). Deletion of Zmynd8 gene in the $\mathrm{CH} 12$ line reduced CSR to IgA (Delgado-Benito et al., 2018). In a conditional mouse model, activated ZMYND8-deficient B cells exhibited a severe defect in CSR to all isotypes tested that was due to defective GLT, while GLT of $\mathrm{S} \mu$ was unaffected (Delgado-Benito et al., 2018). ChIP-Seq analyses revealed that ZMYND8 binds E $\mu$ enhancer and the 3'RR (Delgado-Benito et al., 2018). Importantly, the loss of ZMYND8 led to increased RNAp II loading and transcription at the 3'RR, in particular at hs1,2 and hs3b enhancers, suggesting that ZMYND8 controls the $3^{\prime}$ RR function by down-regulating its transcriptional activity (Delgado-Benito et al., 2018). While these findings reveal that deregulated transcription within the $3^{\prime} R R$ affects its activity, the 
mechanism by which ZMYND8 binding to the $3^{\prime} R R$ regulates GLT remains unclear. This binding appears to not alter the long-range interactions of the $3^{\prime} R R$ (Delgado-Benito et al., 2018). It was proposed that ZMYND8-mediated suppression of RNAp II loading on the 3'RR enhancer may favor GLT by suppressing competition for transcription factors (Delgado-Benito et al., 2018).

In conclusion, the transcriptional activity of the $3^{\prime} R R$ is important for its regulatory function. The $3^{\prime} R R$ has only a marginal effect on the chromatin profile of $S \mu$ region. In contrast, the $3^{\prime} R R$ plays a major role in GLT initiation and the set up of histone modifications at the activated acceptor S regions.

\subsection{Long-range interactions at the $\mathrm{IgH}$ constant region}

The chromatin interaction landscape plays a critical role in regulating cell-type-specific epigenetic control of gene expression. Enhancer-promoter interactions are generally confined within submegabase sized topologically associating domains (TADs), within which these interactions occur at relatively higher frequency than with elements located in different TADs (Dekker and Mirny, 2016; Rowley and Corces, 2018). The TADs are often segregated from each other by chromatin interactions between boundaries enriched in CBEs that can also bind the Cohesin complex. CTCF and Cohesin tether the bases of loops and prevent ectopic enhancerpromoter interactions (Dekker and Mirny, 2016; Hnisz et al., 2016; Rowley and Corces, 2018; Schoenfelder and Fraser, 2019). However, long-range interactions are not always blocked by Cohesin and CTCF binding to CBEs, indicating that many of these sites do not demarcate physically insulated gene domains (Sanyal et al., 2012) and some of these sites can facilitate gene activation (Dekker and Mirny, 2016; Hinsz et al., 2016; Rowley and Corces, 2018). CTCF juxtaposes TAD boundaries in an orientation-dependent manner, with a strong bias for convergent CBEs (de Wit et al., 2015; Guo et al., 2015; Rao et al., 2014; Sanborn et al., 2015). 
Within TADs, Cohesin and the Mediator complexes play an important role in the formation of chromatin loops between enhancers and target promoters. The cohesin-loading factor NIPBL binds the Mediator complex and loads Cohesin at these loops (Kagey et al., 2010; PhillipsCremins et al., 2013. Reviewed in Allen and Taatjes, 2015; Heinz et al., 2015; Soutourina, 2018; Spitz and Furlong, 2012).

In pro-B cells, the IgH locus spans a multi-megabase-sized TAD that could be divided into three sub-TADs, one of which extends from $3^{\prime} \mathrm{CBEs}$ to, and including, the proximal $V_{H}$ domain (Montefiori et al., 2016). In mature B cells, most events pertinent to GLT and CSR occur within that sub-TAD and essentially in the chromatin domain that extends from $E \mu$ region to the 3'CBEs (Fig. 2, see section 2).

In its broad lines, the current paradigm is based on the notion that given the large distances between the critical elements required for GLT and CSR, some kind of inducible long-range interactions, through chromatin looping for instance, are necessary to bring these elements close to each other. Although this notion was hanging in the air, the first evidence in support of it came from $3 \mathrm{C}$ assays designed to detect long-range interactions between transcriptional regulatory elements in the $C_{H}$ region (Wuerfell et al., 2007). The $\mathrm{E} \mu$ enhancer was found to be associated with the $3^{\prime} R R$ in unstimulated and in activated B cells. In unstimulated B cells, $E \mu$, the $3^{\prime} R R$ and I promoters were found in a configuration that was poised for GLT activation, with $I \gamma 3$ promoter displaying the highest association with $E \mu$ and the $3^{\prime} R R$. This poised configuration suggested that the spatial proximity of I promoters later facilitates their activation in response to the specific inducer. Upon stimulation, I promoters were recruited to the $E \mu / 3^{\prime} R R$ complex in a stimulus-dependent manner, juxtaposing $S \mu$ and the acceptor $S$ partner (Wuerfell et al., 2007). Strikingly, deletion of cE $\mu$ had at most a modest effect on E $\mu / 3^{\prime}$ RR association (Wuerfell et al., 2007) (see section 5.4). 
Subsequent studies provided additional insight into the mechanisms underlying formation and stabilization of these chromatin loops. Thus, ChIP-Seq analyses revealed that, in resting B cells, Cohesin and CTCF were recruited to the $3^{\prime}$ CBEs but no significant enrichment was observed at $E \mu$ region. Upon stimulation, Cohesin was recruited, independently of CTCF, to $\mathrm{S} \mu-\mathrm{C} \mu$ region, but not to $\mathrm{E} \mu$ (Thomas-Claudepierre et al., 2013). The functional relevance of the Cohesin complex for CSR was determined in $\mathrm{CH} 12$ line. Knock-down of the core subunits of the Cohesin complex (SMC1 and SMC3) or the loader/unloader subunits, NIPBL and WAPAL, did not impair S $\alpha$ GLT but significantly reduced CSR to IgA, indicating that the Cohesin complex was required for efficient CSR, though seemingly not by regulating S $\alpha$ GLT (Thomas-Claudepierre et al., 2013).

The potential involvement of Mediator complex in GLT and CSR was also investigated. In resting B cells, MED1 and MED12 subunits were exclusively recruited to $E \mu$ and 3'RR enhancers hs1,2 and hs4 (Thomas-Claudepierre et al., 2016). After stimulation, MED1 and MED12 were in addition recruited to the $3^{\prime} \gamma 1 \mathrm{E}$ enhancer and the induced I promoter (Thomas-Claudepierre et al., 2016; Wang et al., 2014), indicating a dynamic recruitment of Mediator complex to I promoters in a stimulation-dependent manner (Thomas-Claudepierre et al., 2016). Knockdown of Med1 or Med12 in $\mathrm{CH} 12$ cells significantly reduced CSR to IgA, which correlated with decreased S $\alpha$ GLT. In a conditional knock-out of Med1, GLT of all acceptor S regions and CSR to the corresponding isotypes were reduced in activated B cells, a clear indication that the Mediator complex promoted GLT of acceptor S regions (Thomas-Claudepierre et al., 2016). In agreement with previous findings (Wuerfell et al., 2007), 4C-Seq experiments on resting B cells revealed a strong interaction between $E \mu$ and $3^{\prime} \mathrm{RR}$ and a preferential association of $\mathrm{l} \gamma 3$ region. After stimulation, $E \mu / 3^{\prime} R R$ interaction was strengthened and additionally included the $3^{\prime} \gamma 1 \mathrm{E}$ and the activated I promoter, in a pattern that correlated well with MED1 and MED12 binding. In MED1-depleted B cells, E $\mu$ interactions with the 3' $\gamma 1 \mathrm{E}$ enhancer and the induced I promoter 
were reduced, implicating Mediator complex in these long-range interactions (ThomasClaudepierre et al., 2016). Together, the above studies suggest that Mediator complex, possibly with Cohesin complex, promotes GLT of acceptor S regions and their long-range interactions with $\mathrm{g} g \mathrm{H}$ transcriptional control elements (Thomas-Claudepierre et al., 2016).

It remains however unclear if $E \mu / 3^{\prime} R R$ interactions in resting $B$ cells require the Mediator complex and to what extent Mediator complex is required for CSR. CSR was reduced by about half in Med1-deficient B cells suggesting MED1-independent mechanisms (ThomasClaudepierre et al., 2016). The situation is complicated by the fact that the composition of Mediator complex is labile, its core subunits can bind different transcription factors, and its composition can change through the loss or acquisition of subunits (Allen and Taatjes, 2015; Heinz et al., 2015; Soutourina, 2018). Recent work strongly suggests that it is Cohesin rather than Mediator that is required for enhancer-promoter contacts, Mediator impacts these contacts indirectly by recruiting architectural factors (El Khattabi et al., 2019). Further investigations are necessary to clarify the role of Mediator complex in GLT and CSR.

\subsection{Loop extrusion and class switch recombination centre}

In its simplest form, the loop extrusion model (Alipour and Marko, 2012; Fudenberg et al., 2016; Nasmyth, 2001; Nichols and Corces, 2015; Sanborn et al., 2015) posits that the ringshaped cohesin complex binds and passes chromatin through its lumen to form a loop, until it reaches the CTCF homodimer at convergent CBEs (Dekker and Merny, 2016; Rowley and Corces, 2018; Schoenfelder and Fraser, 2019; Sikorska and Sexton, 2020). In this general model, CTCF homodimer blocks loop extrusion. In the process, the role of Cohesin is not limited to its association with CBEs-bound CTCF, but extends to the interior of the chromatin loop, increasing for instance the interactions between enhancers and promoters (Dekker and Merny, 2016; Rowley and Corces, 2018). Moreover, Cohesin may move past CTCF anchors at 
a low frequency thus escaping constrains of the CTCF loops, potentially enabling long-range interactions between compartmental domains (Dekker and Merny, 2016; Rowley and Corces, 2018).

Two recent ground-breaking studies (Zhang et al., 2019a; Zhang et al., 2019b) provided evidence that the mechanism underlying the long-range control of CSR involves a Cohesinbased impediment of chromatin loop extrusion mediated by specific transcribed $\mathrm{IgH}$ elements.

Two lines of genetic, functional, and mechanistic investigations were conducted. One line took advantage of RAG scanning activity (Lin et al., 2018) by using A-MuLV pro-B lines. The other line addressed the mechanism of CSR in primary B cells and $\mathrm{CH} 12$ line. Both studies combined GRO-Seq, 3C-HTGTS, and ChIP-Seq assays to track nascent transcription, long-range interactions, and loading of NIPBL and the cohesin subunit RAD21, respectively.

In one study, it was shown that a transcribed S region could impede loop extrusion and RAG scanning activity if the scanning activity was directed towards the $C_{H}$ region (Zhang et al., 2019b). To this end, the recombination centre (Schatz and Ji, 2011) of a pro-B line that constitutively transcribes $S \gamma 2 b$ was engineered by deleting the $J_{H}$ cluster, which enforced RAG scanning activity across the $C_{H}$ region (Zhang et al., 2019b). RAG initiated its scanning and a robust activity of RAG was detected at the transcribed $S \gamma 2 \mathrm{~b}$ and the weakly transcribed $3^{\prime} \mathrm{CBEs}$, but not in the regions upstream or downstream of $S \gamma 2 b$, suggesting that the transcribed $S \gamma 2 b$ impeded RAG scanning activity. $3 \mathrm{C}$-HTGTS revealed that, within the $C_{H}$ region, $\mathrm{E} \mu$ interacted with the off-targets of RAG, $S \gamma 2 b$ and the 3 'CBEs, and this was associated with strong binding of RAD21 at 3'CBEs, and lower accumulation at $\mathrm{E} \mu-\mathrm{S} \mu$ and $\mathrm{l} \gamma 2 \mathrm{~b}-\mathrm{S} \gamma 2 \mathrm{~b}$ regions (Zhang et al., 2019b). Insertion of sequential sites of dead Cas9 in S $\gamma 1$ region, predicted to generate a nonCBE-based scanning impediment, reduced RAG scanning downstream of dead Cas9 sites/S $\gamma 1$ and moderately reduced $\mathrm{S} \gamma 2 \mathrm{~b}$ transcription. $\mathrm{E} \mu$ now robustly interacted with dead Cas9 
sites/S $\gamma 1$ and reduced its interactions with the downstream $S \gamma 2 b$ and $3^{\prime} C B E s$, and surprisingly, RAD21 now additionally accumulated at the dead Cas9 sites/S $\gamma 1$.

The notion that transcription targets RAG scanning activity at $S \gamma 2 b$ was tested by deleting $l \gamma 2 b$ promoter. As expected, the deletion abolished transcription of $S \gamma 2 b$, but it also abrogated RAG scanning, E $\mu$ interactions and RAD21 accumulation at $S \gamma 2 b$. As expected from the removal of an impediment to RAG scanning, an increased activity of RAG was detected at the 3'CBEs (Zhang et al., 2019b). Together, these findings support a model whereby S $\gamma 2 \mathrm{~b}$ transcription impedes upstream and downstream loop extrusions. In the process, $5 \gamma 2 b$ becomes an offtarget during the enforced RAG downstream scanning (Zhang et al., 2019b).

The other study was performed in AID-deficient background to get ride of confounding effects associated with DNA rearrangements during CSR. In resting B cells, robust transcription occurred at $E \mu$ region and the 3'RR essentially, and interactions between E $\mu$ region, 3'RR and 3'CBEs were detected, forming what was termed a class switch recombination centre (CSRC) (Zhang et al., 2019a). NIPBL and RAD21 accumulated at E $\mu$ region, 5'hs1RI, 3'RR and 3'CBEs. After anti-CD40+IL4 stimulation, transcription was induced at $\gamma 1$ and, to a lesser extent, $\varepsilon$ regions, and interactions between $E \mu$ region, $3^{\prime} R R$ and $3^{\prime} C B E s$ now included $\gamma 1$ and $\varepsilon$ regions. NIPBL and RAD21 additionally accumulated at transcribed $\gamma 1$ and $\varepsilon$ regions. RAD21 accumulation pattern mirrored transcription pattern. Notably, there was reduced accumulation at $\mathrm{E} \mu \mathrm{S} \mu$ region and 3'RR (Thomas-Claudepierre et al., 2013; Zhang et al., 2019a). These findings suggested that Cohesin-loading at transcribed S regions contribute to ongoing $3^{\prime} R R-3^{\prime} C B E s$ domain extrusion that leads to $S$ regions alignement for CSR, and potentially competition of activated I promoters for enhancer activity (Zhang et al., 2019a). In resting and activated cells, hs 4 interacted with other $3^{\prime}$ RR enhancers indicating that internal extrusions occur within the $3^{\prime} R R$ (Zhang et al., 2019a). Overall, the data suggested that competition of I promoters for 3'RR activity occurred via loop-extrusion potentially generating 
impediments to induced internal extrusions within the $3^{\prime} R R-3^{\prime} C B E s$ sub-loop that promote directional alignment of $\mathrm{S} \mu$ and transcribed acceptor $\mathrm{S}$ regions within the CSRC (Zhang et al., 2019a).

Further mechanistic analyses were performed in AID-deficient $\mathrm{CH} 12 \mathrm{~F} 3$ cell line. GRO-Seq analyses on both unstimulated and stimulated cells revealed transcription of I $\mu$-C $\delta$ region, constitutive transcription across $S \alpha$ region, and robust transcription at the $3^{\prime} R R$ that (in contrast to primary B cells) extended 24 kb downstream (Zhang et al., 2019a), suggesting that constitutive GLT of S $\alpha$ in CH12 cells is driven by a pre-activated 3'RR (Kim et al., 2016 ; Santos et al., 2019b ; Zhang et al., 2019a). In both non-activated and activated CH12 cells, interactions between transcribed $I \mu-C \mu, I \alpha-C \alpha, 3^{\prime} R R$ and proximal $3^{\prime} C B E s$ regions were detected but did not extend to transcribed sequences downstream of the $3^{\prime}$ CBEs. Consistent with constitutive GLT of S $\alpha$, NIPBL and cohesin notably accumulated at l $\alpha$ (Zhang et al., 2019a).

Thus, from an I promoter point of view, $\mathrm{CSRC}$ interactions in $\mathrm{CH} 12$ line exhibit a predominance of $l \alpha$, which precludes activation of upstream promoters. One prediction of this notion is that breaking the monopoly of I $\alpha$ in CSRC interactions would offer a chance to upstream, extruded I promoters to be transcriptionally activated by newly generated CSRC interactions. This was tested by deleting l $\alpha$ promoter (Zhang et al., 2019a). As expected, deletion of l $\alpha$ promoter abrogates CSR to $\mathrm{S} \alpha$, and leads to low to moderate increase in GLT of and CSR to upstream S regions (Santos et al., 2019b; Zhang et al., 2019a). Consistent with transcription patterns, deletion of I $\alpha$ eliminated $\mathrm{E} \mu$ - and hs4-mediated CSRC interactions with I $\alpha$-C $\alpha$, and significantly increased interactions of $\mathrm{E} \mu$ and hs 4 regions with upstream, $\mathrm{C} \delta$-S $\alpha$ intervening region (Zhang et al., 2019a).

Another prediction of the above notion is that insulation of $1 \alpha$ promoter from upstream influence would impact loop extrusion-mediated CSR. That was indeed the case. Insertion of 3 CBEs downstream of $C \gamma 2 a$ in a convergent orientation to the $3^{\prime}$ CBEs reduced S $\alpha$ CSR, 
suggesting that the ectopic CBEs impeded loop extrusion. RAD21 accumulated at the ectopic CBEs, which gained interactions with 3 'CBEs, $\mathrm{E} \mu$ and $\mathrm{I} \alpha-\mathrm{C} \alpha$ regions. $\mathrm{E} \mu$ on the other hand interacted with the ectopic CBEs, I $\alpha-C \alpha, 3^{\prime}$ RR and $3^{\prime}$ CBEs regions. If now l $\alpha$ promoter is deleted, interactions of the ectopic CBEs with I $\alpha$-C $\alpha$ region are disrupted, but not those with the $3^{\prime}$ RR-3'CBEs domain. Except for the loss of interactions with l $\alpha-C \alpha$ region, the pattern of interactions of $\mathrm{E} \mu$ and hs4 did not change (Zhang et al., 2019a).

These and other considerations (Zhang et al., 2019a) led to a model whereby E $\mu$ and 3'RR enhancers, which are Cohesin-loading sites, dynamically impede loop extrusion (Fig. 5). The impediment ultimately brings $E \mu-S \mu$ region and the $3^{\prime} \mathrm{RR}-3^{\prime} \mathrm{CBEs}$ into proximity to form a CSRC. Induction of CSR primes an I promoter and its associated S region becomes highly transcribed when associated with CSRC enhancers via ongoing loop extrusion. Within the CSRC, the highlevel transcription promotes Cohesin loading and additional extrusions for synapsis with $\mathrm{S} \mu$ and AID targeting to initiate CSR (Zhang et al., 2019a) (Fig. 5). Thus, in addition to their function as transcriptional enhancers, $\mathrm{E} \mu$ and the $3^{\prime} \mathrm{RR}$ may have an additional function, that of loop extrusion impediments.

As with any ground-breaking model, the proposed model explains many lingering issues (Zhang et al., 2019a), opens various paths and raises several questions. For instance, while the role of the $3^{\prime} \mathrm{RR}$ in CSR is well established, the role of E $\mu$ enhancer is less clear as its deletion has at most a marginal effect on GLT and CSR (Marquet et al., 2014; Perlot et al., 2005; Sakai et al., 1999; Wuerfell et al., 2007) and does not significantly alter 3'RR interactions with $\mathrm{S} \mu$ region as monitored by $3 C$ assays (Wuerfell et al., 2007). Thus, of the two elements, $\mathrm{E} \mu$ and $3^{\prime} R R$, the $3^{\prime} R R$ (with the assisting $3^{\prime} C B E s$ ) is likely the master organizer, potentially aided in that by its capacity to provide abundant sites for Cohesin-loading and loop extrusion between 3'RR enhancers. This would imply that extrusion of the large, $C_{H}$-containing loop, starts more frequently from the $3^{\prime}$ end. On the upstream part of the loop, it is plausible that, in the absence 
of $E \mu$ (which strongly impairs $V(D) J$ recombination), upstream Cohesin-binding sites of the subTAD such as IGCR1 provide a back-up for loop extrusion impediment. It will be interesting to perform similar analyses in E $\mu$-deficient background. On the other hand, while the 3'CBEs may contribute to CSRC synapsis functions, implication of upstream V(D)J-E $\mu$ locale (Zhang et al., 2019a) should take into account the fact that partially rearranged $D_{H}$ alleles can undergo CSR, and may involve upstream Cohesin-binding sites.

Besides $\mathrm{E} \mu$ enhancer, the two other long-range interacting, Cohesin-loading elements, $3^{\prime} \gamma 1 \mathrm{E}$ and 5'hs1RI, regulate GLT of and CSR to a subset of isotypes (Amoretti-Villa et al., 2019; Braikia et al., 2017). How they contribute to loop extrusion impediment is presently unclear.

Competition of I promoters for 3'RR activity was inferred from analyses of B cell populations (e.g. Braikia et al., 2017; Cogné et al., 1994; Manis et al., 1998; Oruc et al., 2007; Seidl et al., 1999). However, analysis of GLT on a monoallelic basis showed that competition was not a general rule. In LPS-activated primary B cells, $1 \gamma 3$ and $1 \gamma 2 b$ promoters were co-activated (Santos et al., 2019a) (see section 5.1). In fact, the standard model imposes a strict competition between two transcribed S regions in that only one will ultimately synapse with $\mathrm{S} \mu$, but for two I promoters, proximity with enhancers within a CSRC may be sufficient for coactivation (e.g. discussion in El Khattabi et al., 2019, and Furlong and Levine, 2018).

Future investigations should help clarify these issues and are likely to refine the standard model.

\section{The IncCSR ${ }^{I g A}$ locus}

Enhancer transcripts (eRNAs) are non-coding RNAs thought to be essential for enhancer activity although the mechanisms of action are still unclear. eRNAs may be involved in gene expression by stabilizing or traping factors that bind enhancer. eRNAs have also been implicated in the release of paused RNAp II to allow for productive transcription elongation. 
They have also been implicated in the formation and stabilization of chromatin loops that facilitate enhancer-promoter interactions (Li et al., 2016). Some of the eRNAs are substrates of the RNA surveillance machinery, the RNA exosome, and although eRNAs levels are generally low compared to the messenger RNAs of their target genes, exosome-sensitive eRNAs can be more easily studied in the absence of the RNA exosome (Nair et al., 2020).

In this context, recent investigations on the role of RNA exosome in B cells revealed a unanticipated mechanism involving chromatin interactions between the $3^{\prime}$ RR and a non-lg locus that influence CSR (Pefanis et al., 2015). RNA surveillance machinery was ablated in B cells by conditional mutagenesis of two subunits of the RNA exosome. RNA-Seq and transcriptomes analyses revealed that exosome-deficient transcriptomes were enriched in non-coding RNAs genome wide. In particular, one exosome-sensitive IncRNA was expressed in a region $\sim 2.6 \mathrm{Mb}$ downstream of the $3^{\prime} \mathrm{RR}$, and its locus (hereafter $\operatorname{Inc} C S R^{\operatorname{IgA}}$ ) turned out to be a divergent eRNA-expressing element, which interacted with hs4 enhancer of the $3^{\prime} \mathrm{RR}$ as detected by $3 C$ assay (Pefanis et al., 2015). Deletion of the IncCSR ${ }^{I g A}$ locus in $\mathrm{CH} 12$ cells reduced S $\alpha$ GLT and IgA CSR, and substantially decreased the interaction frequency between the deleted locus and hs4 enhancer (Pefanis et al., 2015). In IncCSR ${ }^{I g A}$-deficient mice, Peyer's patches B cells showed reduced IgA CSR, and activated splenic B cells had a CSR defect to $\operatorname{IgG} 2 \mathrm{~b}$ and IgA specifically (Rothschild et al., 2020). The IncCSR ${ }^{\lg A}$ is flanked by two divergent IncRNA-expressing elements, termed locus $A$ and locus $B$, and the three loci are flanked by Cohesin- and CBEs. The IncCSR IgA locus was enriched in H3K27Ac and H3K4me1 marks, MED1 binding and DNase I hypersensitivity, suggestive of an enhancer element (Rothschild et al., 2020). Hi-C and 4C-Seq assays revealed that the three loci exist in a single TAD, termed TAD ${ }^{\text {IncCSRlgA }}$, separated from the IgH TAD by other TADs. The CBE neighboring the IncCSR $R^{I g A}$ locus interacts with locus $A$ and locus $B$ sequences, but when the $\operatorname{IncCS} R^{\lg A}$ locus is deleted, the interaction with locus $B$ sequence becomes stronger, while interaction with locus $A$ is 
unaffected, suggesting a CBE-mediated interaction between $\operatorname{IncCSR}{ }^{\lg A}$ and locus $B$, whose strength is weakened by transcription of the $\operatorname{IncCSR^{IgA}}$ locus. The CBE of the IncCSR ${ }^{\lg A}$ locus was also shown by $3 C$ assay to interact with hs 4 region of the $3^{\prime} R R$, and the interaction frequency dropped upon deletion of the $\operatorname{IncCSR} R^{\lg A}$ locus. Nonetheless, the inter-TAD interaction frequencies were overall weaker than intra-TAD interactions (Rothschild et al., 2020).

The relevance of the IncCSR ${ }^{I g A}$ locus and flanking CBE, locus $A$, and locus $B$ for CSR was investigated in $\mathrm{CH} 12$ cells by a series of individual and combined knock-outs, knock-down of the IncCSR IgA RNA, and rescue experiments (Pefanis et al., 2015, Rothschild et al., 2020). Together, the data suggested that the $\operatorname{IncCSR}{ }^{I g A} C B E$ could be pivotal in the intra-TAD ${ }^{\text {IncCSRlgA }}$ interactions required for efficient IgA CSR (Rothschild et al., 2020). Biochemical and ChIP assays revealed that the IncCSR IgA ncRNA recruits the SMC3 subunit of the Cohesin complex, the SUPT16H subunit of FACT, and PARP1 at the pivotal IncCSR ${ }^{I g A} \mathrm{CBE}$.

Together, the data are consistent with a model whereby the transcribed enhancer-like IncCSR IgA element produces a IncRNA that facilitates the recruitment of regulatory proteins to the neighboring $C B E$ thus altering intra-TAD ${ }^{\operatorname{lnc} C S R I g A}$ interactions as well as interactions with the 3'RR (Rothschild et al., 2020).

These original studies potentially reveal a novel mechanism whereby interactions within a distant TAD influence the 3'RR-mediated control of CSR within a different TAD. Nonetheless, the mechanism by which CSR is impaired in the absence of the IncCSR ${ }^{\operatorname{Ig} A}$ RNA remains unclear and the future investigations (Rothschild et al., 2020) should help elucidate the mechanism. A potential caveat is that deletion of the interacting partner, hs4 region, in mice has no effect on CSR (Vincent-Faber et al., 2009). This could however be accomodated by the potential involvement of upstream 3'RR enhancers. In this regard, the defect in CSR to IgG2b and IgA in activated $\operatorname{IncCSR}{ }^{I g A}$-deficient B cells is suggestive. From the $3^{\prime} \mathrm{RR}$ side, no individual enhancer 
deletion has an effect on CSR, whereas deletion of more than one does (Fig. 2). It is unfortunate that the sense and antisense transcripts running across the $3^{\prime} R R$ have not been mapped yet. A precise map should help in identifying the RNA-protein complexes potentially involved in this mechanism.

\section{Perspectives}

Over the past few years, important advances have been achieved in understanding the longrange mechanisms underlying CSR, aided in that by the development of various high throughput technologies. These, together with the identification of new cis-acting elements and elucidation of their role in CSR, revealed multiple layers of regulation of the process, including transcriptional and epigenetic mechanisms and higher order chromatin dynamics. Despite important advances, many issues remain to be investigated. Far from being exhaustive and besides questions already raised in this review, the following list merely indicates few of many long-standing questions.

For instance, how do the chromatin loops form, what are the signals that trigger them or cause them to collapse, and how all this is connected to GLT and CSR ? There is still a large gap between the dynamics of chromatin loops and the fine details of transcription and epigenetic regulation.

The transcriptional activity of the $3^{\prime} \mathrm{RR}$ is apparently required for efficient CSR, but the precise mechanism by which 3'RR eRNAs regulate CSR remains elusive. Additional studies are needed to elucidate their function and their potential involvement in the long-range chromatin interactions involving $\lg H$ enhancers.

The loop extrusion/CSRC model will likely provide the framework for many investigations to come. While we focused on the major role of enhancers and Cohesin in this process, this 
obviously does not exclude the implication of other regulatory factors that bind these enhancers such as YY1 thought to impede Cohesin-mediated loop extrusion to facilitate enhancer-promoter interactions. Future studies will bring additional insights into the interplay between transcription factors, the dynamics of chromatin loop extrusion, and their relevance for CSR. 


\section{Acknowledgements}

This work was supported by the Agence Nationale de la Recherche [ANR-16-CE12-0017], the Institut National du Cancer [INCA_9363, PLBI015-134], the Fondation ARC pour la Recherche sur le Cancer [PJA 20191209515], and the Ligue Contre le Cancer (Ligue Régionale : comités de l’Ex Région Midi-Pyrénées). CO is a fellow of the Ministry of Higher Education \& Research, and is recipient of a fellowship from the "Fondation pour la Recherche Médicale". CO thanks the EMBO for an EMBO short-term fellowship. FZB was supported by a fellowship from the Institut National du Cancer.

\section{Compliance with ethics guidelines}

The authors declare no conflict of interest. 


\section{References}

Afshar, R., Pierce, S., Bolland, D.J., Corcoran, A., Oltz, \& E.M., 2006. Regulation of IgH gene assembly: role of the intronic enhancer and 5'DQ52 region in targeting DHJH recombination. J Immunol 176, 2439-2447.

Akira, S., Sugiyama, H., Yoshida, N., Kikutani, H., Yamamura, Y., \& Kishimoto, T., 1983. Isotype switching in murine pre-B cell lines. Cell 34, 545-556.

Alipour, E., \& Marko, J.F. 2012. Self-organization of domain structures by DNA-loop-extruding enzymes. Nucleic Acids Res 40, 11202-11212.

Allahyar, A., Vermeulen, C., Bouwman, B.A.M., Krijger, P.H.L., Verstegen, M., Geeven, G., et al., 2018. Enhancer hubs and loop collisions identified from single-allele topologies. Nat Genet 50, 1151-1160.

Allen, B.L., \& Taatjes, D.J., 2015. The Mediator complex: a central integrator of transcription. Nat Rev Mol Cell Biol 16, 155-166.

Alt, F.W., Rosenberg, N., Casanova, R.J., Thomas, E., \& Baltimore, D., 1982. Immunoglobulin heavychain expression and class switching in a murine leukaemia cell line. Nature 296, 325-331.

Amoretti-Villa, R., Rogier, M., Robert, I., Heyer, V., \& Reina-San-Martin, B., 2019. A novel regulatory region controls IgH locus transcription and switch recombination to a subset of isotypes. Cell $\mathrm{Mol}$ Immunol 16, 887-889.

Arpin, C., de Bouteiller, O., Razanajaona, D., Fugier-Vivier, I., Briere, F., Banchereau, J., et al., 1998. The normal counterpart of IgD myeloma cells in germinal center displays extensively mutated IgVH gene, Cmu-Cdelta switch, and lambda light chain expression. J Exp Med 187, 1169-1178.

Atchison, M.L., 2014. Function of YY1 in Long-Distance DNA Interactions. Front Immunol 5, 45.

Basu, U., Meng, F.L., Keim, C., Grinstein, V., Pefanis, E., Eccleston, J., et al., 2011. The RNA exosome targets the AID cytidine deaminase to both strands of transcribed duplex DNA substrates. Cell 144, 353-363.

Bébin, A.G., Carrion, C., Marquet, M., Cogné, N., Lecardeur, S., Cogné, M., et al., 2010. In vivo redundant function of the $3^{\prime}$ IgH regulatory element $\mathrm{HS} 3 \mathrm{~b}$ in the mouse. J Immunol 184, 3710-3717.

Bell, A.C., West, A.G., \& Felsenfeld, G., 1999. The protein CTCF is required for the enhancer blocking activity of vertebrate insulators. Cell 98, 387-396.

Birshtein, B.K., 2014. Epigenetic Regulation of Individual Modules of the immunoglobulin heavy chain locus 3' Regulatory Region. Front Immunol 5, 163.

Boboila, C., Alt, F.W., \& Schwer, B., 2012. Classical and alternative end-joining pathways for repair of lymphocyte-specific and general DNA double-strand breaks. Adv Immunol 116, 1-49.

Bolland, D.J., Wood, A.L., Afshar, R., Featherstone, K., Oltz, E.M., \& Corcoran, A.E., 2007. Antisense intergenic transcription precedes Igh $\mathrm{D}$-to-J recombination and is controlled by the intronic enhancer Emu. Mol Cell Biol 27, 5523-5533.

Braikia, F.Z., Conte, C., Moutahir, M., Denizot, Y., Cogné, M., \& Khamlichi, A.A., 2015. Developmental Switch in the Transcriptional Activity of a Long-Range Regulatory Element. Mol Cell Biol 35, 3370-3380. 
Braikia, F.Z., Oudinet, C., Haddad, D., Oruc, Z., Orlando, D., Dauba, A., et al., 2017. Inducible CTCF insulator delays the IgH 3 ' regulatory region-mediated activation of germline promoters and alters class switching. Proc Natl Acad Sci U S A 114, 6092-6097.

Burrows, P.D., Beck-Engeser, G.B., \& Wabl, M.R., 1983. Immunoglobulin heavy-chain class switching in a pre-B cell line is accompanied by DNA rearrangement. Nature 306, 243-246.

Calame, K., \& Atchison, M., 2007. YY1 helps to bring loose ends together. Genes Dev 21, 1145-1152.

Callen, E., Di Virgilio, M., Kruhlak, M.J., Nieto-Soler, M., Wong, N., Chen, H.-T., et al., 2013. 53BP1 mediates productive and mutagenic DNA repair through distinct phosphoprotein interactions. Cell $153,1266-1280$.

Casellas, R., Basu, U., Yewdell, W.T., Chaudhuri, J., Robbiani, D.F., \& Di Noia, J.M., 2016. Mutations, kataegis and translocations in B cells: understanding AID promiscuous activity. Nat Rev Immunol 16, 164-176.

Casola, S., Cattoretti, G., Uyttersprot, N., Koralov, S.B., Seagal, J., Hao, Z., et al., 2006. Tracking germinal center $B$ cells expressing germ-line immunoglobulin gamma1 transcripts by conditional gene targeting. Proc Natl Acad Sci U S A 103, 7396-7401.

Ceredig, R., \& Rolink, A.G., 2012. The key role of IL-7 in lymphopoiesis. Semin Immunol 24, 159-164.

Chakraborty, T., Perlot, T., Subrahmanyam, R., Jani, A., Goff, P.H., Zhang, Y., et al., 2009. A 220 nucleotide deletion of the intronic enhancer reveals an epigenetic hierarchy in immunoglobulin heavy chain locus activation. J Exp Med 206, 1019-1027.

Chaudhuri, J., \& Alt, F.W., 2004. Class-switch recombination: interplay of transcription, DNA deamination and DNA repair. Nat Rev Immunol 4, 541-552.

Chaudhuri, J., Basu, U., Zarrin, A., Yan, C., Franco, S., Perlot, T., et al., 2007. Evolution of the immunoglobulin heavy chain class switch recombination mechanism. Adv Immunol 94, 157-214.

Chauveau, C., \& Cogné, M., 1996. Palindromic structure of the IgH 3'locus control region. Nat Genet $14,15-16$.

Chen, K., \& Cerutti, A., 2010. New insights into the enigma of immunoglobulin D. Immunol Rev 237, 160-179.

Chen, Z., \& Wang, J.H., 2019. Signaling control of antibody isotype switching. Adv Immunol 141, 105164.

Clark, M.R., Mandal, M., Ochiai, K., \& Singh, H., 2014. Orchestrating B cell lymphopoiesis through interplay of IL-7 receptor and pre-B cell receptor signalling. Nat Rev Immunol 14, 69-80.

Cobaleda, C., Schebesta, A., Delogu, A., \& Busslinger, M., 2007. Pax5: the guardian of B cell identity and function. Nat Immunol 8, 463-470.

Cogné, M., Lansford, R., Bottaro, A., Zhang, J., Gorman, J., Young, F., et al., 1994. A class switch control region at the $3^{\prime}$ end of the immunoglobulin heavy chain locus. Cell 77, 737-747.

Core, L., \& Adelman, K., 2019. Promoter-proximal pausing of RNA polymerase II: a nexus of gene regulation. Genes Dev 33, 960-982. 
Corfe, S.A., \& Paige, C.J., 2012. The many roles of IL-7 in B cell development; mediator of survival, proliferation and differentiation. Semin Immunol 24, 198-208.

Dalloul, I., Boyer, F., Dalloul, Z., Pignarre, A., Caron, G., Fest, T., et al., 2019. Locus suicide recombination actively occurs on the functionally rearranged IgH allele in B-cells from inflamed human lymphoid tissues. PLoS Genet 15, e1007721.

Daniel, J.A., \& Nussenzweig, A., 2013. The AID-induced DNA damage response in chromatin. Mol Cell 50, 309-321.

Daniel, J.A., Santos, M.A., Wang, Z., Zang, C., Schwab, K.R., Jankovic, M., et al., 2010. PTIP promotes chromatin changes critical for immunoglobulin class switch recombination. Science 329, 917-923.

Dauba, A., Braikia, F.Z., Oudinet, C., \& Khamlichi, A.A., 2020. Interleukin 7 regulates switch transcription in developing B cells. Cell Mol Immunol. Apr 16. doi: 10.1038/s41423-020-0430-y.

de Wit, E., Vos, E.S., Holwerda, S.J., Valdes-Quezada, C., Verstegen, M.J., Teunissen, H., et al., 2015. CTCF Binding Polarity Determines Chromatin Looping. Mol Cell 60, 676-684.

Degner, S.C., Verma-Gaur, J., Wong, T.P., Bossen, C., Iverson, G.M., Torkamani, A., et al., 2011. CCCTCbinding factor (CTCF) and cohesin influence the genomic architecture of the Igh locus and antisense transcription in pro-B cells. Proc Natl Acad Sci U S A 108, 9566-9571.

Degner, S.C., Wong, T.P., Jankevicius, G., \& Feeney, A.J., 2009. Cutting edge: developmental stagespecific recruitment of cohesin to CTCF sites throughout immunoglobulin loci during B lymphocyte development. J Immunol, 182, 44-48.

Dekker, J., \& Mirny, L., 2016. The 3D Genome as Moderator of Chromosomal Communication. Cell 164, $1110-1121$.

Delgado-Benito, V., Rosen, D.B., Wang, Q., Gazumyan, A., Pai, J.A., Oliveira, T.Y., et al., 2018. The Chromatin Reader ZMYND8 Regulates Igh Enhancers to Promote Immunoglobulin Class Switch Recombination. Mol Cell 72, 636-649.e638.

Delpy, L., Le Bert, M., Cogné, M., \& Khamlichi, A.A., 2003. Germ-line transcription occurs on both the functional and the non-functional alleles of immunoglobulin constant heavy chain genes. Eur $J$ Immunol 33, 2108-2113.

Di Noia, J.M., \& Neuberger, M.S., 2007. Molecular mechanisms of antibody somatic hypermutation. Annu Rev Biochem 76, 1-22.

Edry, E., Azulay-Debby, H., \& Melamed, D., 2008. TOLL-like receptor ligands stimulate aberrant class switch recombination in early B cell precursors. Int Immunol 20, 1575-1585.

Edry, E., Koralov, S.B., Rajewsky, K., \& Melamed, D., 2007. Spontaneous class switch recombination in $B$ cell lymphopoiesis generates aberrant switch junctions and is increased after VDJ rearrangement. J Immunol 179, 6555-6560.

Ehrenstein, M.R., \& Notley, C.A., 2010. The importance of natural IgM: scavenger, protector and regulator. Nat Rev Immunol 10, 778-786.

El Khattabi, L., Zhao, H., Kalchschmidt, J., Young, N., Jung, S., Van Blerkom, P., et al., 2019. A Pliable Mediator Acts as a Functional Rather Than an Architectural Bridge between Promoters and Enhancers. Cell 178, 1145-1158 e1120. 
Ernst, P., \& Smale, S.T., 1995. Combinatorial regulation of transcription II: The immunoglobulin mu heavy chain gene. Immunity 2, 427-438.

Featherstone, K., Wood, A.L., Bowen, A.J., \& Corcoran, A.E., 2010. The mouse immunoglobulin heavy chain $V$ - $D$ intergenic sequence contains insulators that may regulate ordered $V(D) J$ recombination. The J Biol Chem 285, 9327-9338.

Fudenberg, G., Imakaev, M., Lu, C., Goloborodko, A., Abdennur, N., \& Mirny, L.A., 2016. Formation of Chromosomal Domains by Loop Extrusion. Cell Rep 15, 2038-2049.

Fukaya, T., Lim, B., \& Levine, M., 2016. Enhancer Control of Transcriptional Bursting. Cell 166, 358-368.

Furlong, E.E.M., \& Levine, M., 2018. Developmental enhancers and chromosome topology. Science $361,1341-1345$.

Garot, A., Marquet, M., Saintamand, A., Bender, S., Le Noir, S., Rouaud, P., et al., 2016. Sequential activation and distinct functions for distal and proximal modules within the IgH 3 ' regulatory region. Proc Natl Acad Sci U S A 113, 1618-1623.

Garrett, F.E., Emelyanov, A.V., Sepulveda, M.A., Flanagan, P., Volpi, S., Li, F., Loukinov, D., et al., 2005. Chromatin architecture near a potential $3^{\prime}$ end of the igh locus involves modular regulation of histone modifications during B-Cell development and in vivo occupancy at CTCF sites. Mol Cell Biol 25, 15111525.

Ghazzaui, N., Issaoui, H., Boyer, F., Martin, O.A., Saintamand, A., \& Denizot, Y., 2019. 3'RR and 5'E $\mu$ Immunoglobulin Heavy Chain Enhancers Are Independent Engines of Locus Remodeling. Cell Mol Immunol 16, 198-200.

Ghazzaui, N., Issaoui, H., Saintamand, A., Oblet, C., Carrion, C, \& Denizot, Y., 2018. The Immunoglobulin Heavy Chain 3' Regulatory Region Superenhancer Controls Mouse B1 B-cell Fate and Late VDJ Repertoire Diversity. Blood Adv 2, 252-262.

Giambra, V., Volpi, S., Emelyanov, A.V., Pflugh, D., Bothwell, A.L., Norio, P., et al., 2008. Pax5 and linker histone $\mathrm{H} 1$ coordinate DNA methylation and histone modifications in the 3 ' regulatory region of the immunoglobulin heavy chain locus. Mol Cell Biol 28, 6123-6133.

Gilliam, A.C., Shen, A., Richards, J.E., Blattner, F.R., Mushinski, J.F., \& Tucker, P.W., 1984. Illegitimate recombination generates a class switch from $\mathrm{C}$ mu to $\mathrm{C}$ delta in an IgD-secreting plasmacytoma. Proc Natl Acad Sci U S A 81, 4164-4168.

Gostissa, M., Yan, C.T., Bianco, J.M., Cogné, M., Pinaud, E., \& Alt, F.W., 2009. Long-range oncogenic activation of Igh-c-myc translocations by the Igh 3' regulatory region. Nature 462, 803-807.

Guo, C., Yoon, H.S., Franklin, A., Jain, S., Ebert, A., Cheng, H.L., et al., 2011. CTCF-binding elements mediate control of $\mathrm{V}(\mathrm{D}) \mathrm{J}$ recombination. Nature $477,424-430$.

Guo, Y., Xu, Q., Canzio, D., Shou, J., Li, J., Gorkin, D.U., et al., 2015. CRISPR Inversion of CTCF Sites Alters Genome Topology and Enhancer/Promoter Function. Cell 162, 900-910.

Haddad, D., Puget, N., Laviolette-Malirat, N., Conte, C., \& Khamlichi, A.A., 2011. Seking sense of antisense transcripts. Transcription 2, 183-188.

Han, J.H., Akira, S., Calame, K., Beutler, B., Selsing, E., \& Imanishi-Kari, T., 2007. Class switch recombination and somatic hypermutation in early mouse $B$ cells are mediated by $B$ cell and Toll-like receptors. Immunity $27,64-75$. 
Hasan, M., Polic, B., Bralic, M., Jonjic, S., \& Rajewsky, K., 2002. Incomplete block of B cell development and immunoglobulin production in mice carrying the muMT mutation on the BALB/c background. Eur J Immunol 32, 3463-3471.

Haughton, G., Arnold, L.W., Bishop, G.A., \& Mercolino, T.J., 1986. The CH series of murine B cell lymphomas: neoplastic analogues of Ly-1+ normal B cells. Immunol Rev 93, 35-51.

Heinz, S., Romanoski, C.E., Benner, C., \& Glass, C.K., 2015. The selection and function of cell typespecific enhancers. Nat Rev Mol Cell Biol 16, 144-154.

Hnisz, D., Day, D.S., \& Young, R.A., 2016. Insulated Neighborhoods: Structural and Functional Units of Mammalian Gene Control. Cell 167, 1188-1200.

Hnisz, D., Shrinivas, K., Young, R.A., Chakraborty, A.K., \& Sharp, P.A., 2017. A Phase Separation Model for Transcriptional Control. Cell 169, 13-23.

Hosokawa, H., \& Rothenberg, E.V., 2018. Cytokines, Transcription Factors, and the Initiation of T-Cell Development. Cold Spring Harb Perspect Biol., 10, a028621.

Issaoui, H., Ghazzaui, N., Saintamand, A., Carrion, C., Oblet, C., \& Denizot, Y., 2018. The IgH 3' regulatory region super-enhancer does not control IgA class switch recombination in the $\mathrm{B} 1$ lineage. Cell $\mathrm{Mol}$ Immunol 15, 289-291.

Janz, S., 2006. Myc translocations in B cell and plasma cell neoplasms. DNA Repair (Amst) 5, 1213-1224.

Johnston, C.M., Wood, A.L., Bolland, D.J., \& Corcoran, A.E., 2006. Complete sequence assembly and characterization of the C57BL/6 mouse Ig heavy chain V region. J Immunol 176, 4221-4234.

Jung, D., Giallourakis, C., Mostoslavsky, R., \& Alt, F.W., 2006. Mechanism and control of V(D)J recombination at the immunoglobulin heavy chain locus. Annu Rev Immunol 24, 541-570.

Kagey, M.H., Newman, J.J., Bilodeau, S., Zhan, Y., Orlando, D.A., van Berkum, N.L., et al., 2010. Mediator and cohesin connect gene expression and chromatin architecture. Nature 467, 430-435.

Kakkis, E., Mercola, M., \& Calame, K., 1988. Strong transcriptional activation of translocated c-myc genes occurs without a strong nearby enhancer or promoter. Nucleic Acids Res 16, 77-96.

Kenter, A.L., 2012. AID targeting is dependent on RNA polymerase II pausing. Semin Immunol 24, 281286.

Khamlichi, A.A., \& Feil, R., 2018. Parallels between Mammalian Mechanisms of Monoallelic Gene Expression. Trends Genet 34, 954-971.

Khamlichi, A.A., Pinaud, E., Decourt, C., Chauveau, C., \& Cogné, M., 2000. The 3' IgH regulatory region: a complex structure in a search for a function. Adv Immunol 75, 317-345.

Kim, A., Han, L., Santiago, G.E., Verdun, R.E., \& Yu, K., 2016. Class-Switch Recombination in the Absence of the IgH 3' Regulatory Region. J Immunol 197, 2930-2935.

Kluin, P.M., Kayano, H., Zani, V.J., Kluin-Nelemans, H.C., Tucker, P.W., Satterwhite, E., \& Dyer, M.J., 1995. IgD class switching: identification of a novel recombination site in neoplastic and normal $B$ cells. Eur J Immunol 25, 3504-3508. 
Kubagawa, H., Mayumi, M., Crist, W.M., \& Cooper, M.D., 1983. Immunoglobulin heavy-chain switching in pre-B leukaemias. Nature 301, 340-342.

Kumar, S., Wuerffel, R., Achour, I., Lajoie, B., Sen, R., Dekker, J., et al., 2013. Flexible ordering of antibody class switch and V(D)J joining during B-cell ontogeny. Genes Dev 27, 2439-2444.

Kumari, G., \& Sen, R., 2015. Chromatin Interactions in the Control of Immunoglobulin Heavy Chain Gene Assembly. Adv Immunol 128, 41-92.

Le Noir, S., Boyer, F., Lecardeur, S., Brousse, M., Oruc, Z., Cook-Moreau, J., et al., 2017. Functional anatomy of the immunoglobulin heavy chain $3^{\prime}$ super-enhancer needs not only core enhancer elements but also their unique DNA context. Nucleic Acids Res 45, 5829-5837.

Li, S.C., Rothman, P.B., Zhang, J., Chan, C., Hirsh, D., \& Alt, F.W., 1994. Expression of I mu-C gamma hybrid germline transcripts subsequent to immunoglobulin heavy chain class switching. Int Immunol 6 , 491-497.

Li, W., Notani, D., \& Rosenfeld, M.G., 2016. Enhancers as non-coding RNA transcription units: recent insights and future perspectives. Nat Rev Genet 17, 207-223.

Lin, S.G., Ba, Z., Alt, F.W., \& Zhang, Y., 2018. RAG Chromatin Scanning During V(D)J Recombination and Chromatin Loop Extrusion are Related Processes. Adv Immunol 139, 93-135.

Maizels, N., \& Gray, L.T., 2013. The G4 genome. PLoS Genet 9, e1003468.

Manis, J.P., van der Stoep, N., Tian, M., Ferrini, R., Davidson, L., Bottaro, A., \& Alt, F.W., 1998. Class switching in B cells lacking 3' immunoglobulin heavy chain enhancers. J Exp Med 188, 1421-1431.

Marina-Zárate, E., Perez-Garcia, A., \& Ramiro, A.R., 2017. CCCTC-Binding Factor Locks Premature IgH Germline Transcription and Restrains Class Switch Recombination. Front Immunol 8, 1076.

Marquet, M., Garot, A., Bender, S., Carrion, C., Rouaud, P., Lecardeur, S., et al., 2014. The Emu enhancer region influences $\mathrm{H}$ chain expression and $\mathrm{B}$ cell fate without impacting IgVH repertoire and immune response in vivo. J Immunol 193, 1171-1183.

Matthews, A.J., Zheng, S., DiMenna, L.J., \& Chaudhuri, J., 2014. Regulation of immunoglobulin classswitch recombination: choreography of noncoding transcription, targeted DNA deamination, and longrange DNA repair. Adv Immunol 122, 1-57.

Maul, R.W., \& Gearhart, P.J., 2010. AID and somatic hypermutation. Adv Immunol 105, 159-191.

Medvedovic, J., Ebert, A., Tagoh, H., Tamir, I.M., Schwickert, T.A., Novatchkova, M., et al., 2013. Flexible long-range loops in the $\mathrm{VH}$ gene region of the Igh locus facilitate the generation of a diverse antibody repertoire. Immunity 39, 229-244.

Meng, F.L., Du, Z., Federation, A., Hu, J., Wang, Q., Kieffer-Kwon, K.R., et al., 2014. Convergent transcription at intragenic super-enhancers targets AID-initiated genomic instability. Cell 159, 15381548.

Methot, S.P., \& Di Noia, J.M., 2017. Molecular Mechanisms of Somatic Hypermutation and Class Switch Recombination. Adv Immunol 133, 37-87.

Mills, F.C., Harindranath, N., Mitchell, M., \& Max, E.E., 1997. Enhancer complexes located downstream of both human immunoglobulin Calpha genes. J Exp Med 186, 845-858. 
Montefiori, L., Wuerffel, R., Roqueiro, D., Lajoie, B., Guo, C., Gerasimova, T., et al., 2016. Extremely Long-Range Chromatin Loops Link Topological Domains to Facilitate a Diverse Antibody Repertoire. Cell Rep 14, 896-906.

Mundt, C.A., Nicholson, I.C., Zou, X., Popov, A.V., Ayling, C., \& Bruggemann, M., 2001. Novel control motif cluster in the IgH delta-gamma 3 interval exhibits $B$ cell-specific enhancer function in early development. J Immunol 166, 3315-3323.

Muramatsu, M., Nagaoka, H., Shinkura, R., Begum, N.A., \& Honjo, T., 2007. Discovery of activationinduced cytidine deaminase, the engraver of antibody memory. Adv Immunol 94, 1-36.

Nair, L., Chung, H., \& Basu, U., 2020. Regulation of long non-coding RNAs and genome dynamics by the RNA surveillance machinery. Nat Rev Mol Cell Biol 21, 123-136.

Nakamura, M., Kondo, S., Sugai, M., Nazarea, M., Imamura, S., \& Honjo, T., 1996. High frequency class switching of an IgM+ B lymphoma clone $\mathrm{CH} 12 \mathrm{~F} 3$ to IgA+ cells. Int Immunol 8, 193-201.

Nasmyth, K., 2001. Disseminating the genome: joining, resolving, and separating sister chromatids during mitosis and meiosis. Annu Rev Genet 35, 673-745.

Nichols, M.H., \& Corces, V.G., 2015. A CTCF Code for 3D Genome Architecture. Cell 162, 703-705.

Ong, C.-T., Corces, V.G., 2014. CTCF: an architectural protein bridging genome topology and function. Nat Rev Genet 15, 234-246.

Ono, S.J., Zhou, G., Tai, A.K., Inaba, M., Kinoshita, K., \& Honjo, T., 2000. Identification of a stimulusdependent DNase I hypersensitive site between the lalpha and Calpha exons during immunoglobulin heavy chain class switch recombination. FEBS Lett 467, 268-272.

Oruc, Z., Boumediene, A., Le Bert, M., \& Khamlichi, A.A., 2007. Replacement of Igamma3 germ-line promoter by Igamma1 inhibits class-switch recombination to IgG3. Proc Natl Acad Sci U S A 104, 2048420489.

Oudinet, C., Braikia, F.Z., Dauba, A., Santos, J.M., \& Khamlichi, A.A., 2019. Developmental regulation of DNA cytosine methylation at the immunoglobulin heavy chain constant locus. PLoS Genet 15, e1007930.

Pavri, R., 2017. R Loops in the Regulation of Antibody Gene Diversification. Genes 8, 154.

Pavri, R., \& Nussenzweig, M.C., 2011. AID targeting in antibody diversity. Adv Immunol 110, 1-26.

Pawlitzky, I., Angeles, C.V., Siegel, A.M., Stanton, M.L., Riblet, R., \& Brodeur, P.H., 2006. Identification of a candidate regulatory element within the $5^{\prime}$ flanking region of the mouse Igh locus defined by proB cell-specific hypersensitivity associated with binding of PU.1, Pax5, and E2A. J Immunol 176, 68396851.

Pefanis, E., Wang, J., Rothschild, G., Lim, J., Kazadi, D., Sun, J., et al., 2015. RNA exosome-regulated long non-coding RNA transcription controls super-enhancer activity. Cell 161, 774-789.

Peled, J.U., Kuang, F.L., Iglesias-Ussel, M.D., Roa, S., Kalis, S.L., Goodman, M.F., \& Scharff, M.D., 2008. The biochemistry of somatic hypermutation. Annu Rev Immunol 26, 481-511.

Perlot, T., \& Alt, F.W., 2008. Cis-regulatory elements and epigenetic changes control genomic rearrangements of the IgH locus. Adv Immunol 99, 1-32. 
Perlot, T., Alt, F.W., Bassing, C.H., Suh, H., \& Pinaud, E., 2005. Elucidation of IgH intronic enhancer functions via germ-line deletion. Proc Natl Acad Sci U S A 102, 14362-14367.

Perlot, T., Pawlitzky, I., Manis, J.P., Zarrin, A.A., Brodeur, P.H., \& Alt, F.W., 2010. Analysis of mice lacking DNasel hypersensitive sites at the 5' end of the IgH locus. PLoS One 5, e13992.

Péron, S., Laffleur, B., Denis-Lagache, N., Cook-Moreau, J., Tinguely, A., Delpy, L., et al., 2012. AIDdriven deletion causes immunoglobulin heavy chain locus suicide recombination in B cells. Science 336, 931-934.

Phillips-Cremins, J.E., Sauria, M.E., Sanyal, A., Gerasimova, T.I., Lajoie, B.R., Bell, J.S., et al., 2013. Architectural protein subclasses shape 3D organization of genomes during lineage commitment. Cell 153, 1281-1295.

Pinaud, E., Aupetit, C., Chauveau, C., \& Cogné, M., 1997. Identification of a homolog of the C alpha $3^{\prime} / \mathrm{hs} 3$ enhancer and of an allelic variant of the $3^{\prime} \operatorname{IgH} / \mathrm{hs} 1,2$ enhancer downstream of the human immunoglobulin alpha 1 gene. Eur J Immunol 27, 2981-2985.

Pinaud, E., Khamlichi, A.A., Le Morvan, C., Drouet, M., Nalesso, V., Le Bert, M., \& Cogné, M., 2001. Localization of the $3^{\prime} \mathrm{IgH}$ locus elements that effect long-distance regulation of class switch recombination. Immunity 15, 187-199.

Pinaud, E., Marquet, M., Fiancette, R., Péron, S., Vincent-Fabert, C., Denizot, Y., \& Cogné, M., 2011. The IgH locus 3' regulatory region: pulling the strings from behind. Adv Immunol 110, 27-70.

Predeus, A.V., Gopalakrishnan, S., Huang, Y., Tang, J., Feeney, A.J., Oltz, E.M., \& Artyomov, M.N., 2014. Targeted chromatin profiling reveals novel enhancers in Ig H and Ig L chain Loci. J Immunol 192, 10641070.

Preud'homme, J.L., Petit, I., Barra, A., Morel, F., Lecron, J.C., \& Lelievre, E., 2000. Structural and functional properties of membrane and secreted IgD. Mol Immunol 37, 871-887.

Proudhon, C., Hao, B., Raviram, R., Chaumeil, J., \& Skok, J.A., 2015. Long-Range Regulation of V(D)J Recombination. Adv Immunol 128, 123-182.

Puget, N., Hirasawa, R., Hu, N.S., Laviolette-Malirat, N., Feil, R., \& Khamlichi, A.A., 2015. Insertion of an imprinted insulator into the IgH locus reveals developmentally regulated, transcription-dependent control of V(D)J recombination. Mol Cell Biol 35, 529-543.

Qian, J., Wang, Q., Dose, M., Pruett, N., Kieffer-Kwon, K.R., Resch, W., et al., 2014. B cell superenhancers and regulatory clusters recruit AID tumorigenic activity. Cell 159, 1524-1537.

Qiao, Q., Wang, L., Meng, F.L., Hwang, J.K., Alt, F.W., \& Wu, H., 2017. AID Recognizes Structured DNA for Class Switch Recombination. Mol Cell 67, 361-373 e364.

Rajagopal, D., Maul, R.W., Ghosh, A., Chakraborty, T., Khamlichi, A.A., Sen, R., \& Gearhart, P.J., 2009. Immunoglobulin switch mu sequence causes RNA polymerase II accumulation and reduces $\mathrm{dA}$ hypermutation. J Exp Med 206, 1237-1244.

Rao, S.S., Huntley, M.H., Durand, N.C., Stamenova, E.K., Bochkov, I.D., Robinson, J.T., et al., 2014. A 3D map of the human genome at kilobase resolution reveals principles of chromatin looping. Cell 159, $1665-1680$. 
Retter, I., Chevillard, C., Scharfe, M., Conrad, A., Hafner, M., Im, T.H., et al., 2007. Sequence and characterization of the Ig heavy chain constant and partial variable region of the mouse strain $129 \mathrm{~S} 1$. J Immunol 179, 2419-2427.

Ribeiro de Almeida, C., Dhir, S., Dhir, A., Moghaddam, A.E., Sattentau, Q., Meinhart, A., \& Proudfoot, N.J., 2018. RNA Helicase DDX1 Converts RNA G-Quadruplex Structures into R-Loops to Promote IgH Class Switch Recombination. Mol Cell 70, 650-662 e658.

Rodriguez, J., \& Larson, D.R., 2020. Transcription in Living Cells: Molecular Mechanisms of Bursting. Annu Rev Biochem. doi: 10.1146/annurev-biochem-011520-105250.

Rothschild, G., Zhang, W., Lim, J., Giri, P.K., Laffleur, B., Chen, Y., et al., 2020. Noncoding RNA transcription alters chromosomal topology to promote isotype-specific class switch recombination. Sci immunol 5, eaay5864.

Rouaud, P., Saintamand, A., Saad, F., Carrion, C., Lecardeur, S., Cogné, M., \& Denizot, Y., 2014. Elucidation of the enigmatic IgD class-switch recombination via germline deletion of the IgH $3^{\prime}$ regulatory region. J Exp Med 211, 975-985.

Rouaud, P., Vincent-Fabert, C., Saintamand, A., Fiancette, R., Marquet, M., Robert, I., et al., 2013. The $\mathrm{IgH} 3$ ' regulatory region controls somatic hypermutation in germinal center B cells. J Exp Med 210, 1501-1507.

Rowley, M.J., \& Corces, V.G., 2018. Organizational principles of 3D genome architecture. Nat Rev Genet $19,789-800$.

Roy, A.L., Sen, R., \& Roeder, R.G., 2011. Enhancer-promoter communication and transcriptional regulation of Igh. Trends Immunol 32, 532-539.

Saintamand, A., Rouaud, P., Saad, F., Rios, G., Cogné, M., \& Denizot, Y., 2015. Elucidation of IgH 3' region regulatory role during class switch recombination via germline deletion. Nat Commun 6, 7084.

Saintamand, A., Vincent-Fabert, C., Garot, A., Rouaud, P., Oruc, Z., Magnone, V., et al., 2016. Deciphering the importance of the palindromic architecture of the immunoglobulin heavy-chain $3^{\prime}$ regulatory region. Nat Commun 7, 10730.

Sakai, E., Bottaro, A., Davidson, L., Sleckman, B.P., \& Alt, F.W., 1999. Recombination and transcription of the endogenous Ig heavy chain locus is effected by the Ig heavy chain intronic enhancer core region in the absence of the matrix attachment regions. Proc Natl Acad Sci U S A 96, 1526-1531.

Sanborn, A.L., Rao, S.S., Huang, S.C., Durand, N.C., Huntley, M.H., Jewett, A.I., et al., 2015. Chromatin extrusion explains key features of loop and domain formation in wild-type and engineered genomes. Proc Natl Acad Sci U S A 112, E6456-6465.

Santos, J.M., Braikia, F.-Z., Oudinet, C., Haddad, D., Conte, C., Dauba, A., \& Khamlichi, A.A., 2018. Duplication of a germline promoter downstream of the IgH 3 ' regulatory region impairs class switch recombination. Sci Rep 8, 9164.

Santos, J.M., Braikia, F.Z., Oudinet, C., Dauba, A., \& Khamlichi, A.A., 2019a. Two modes of cis-activation of switch transcription by the IgH superenhancer. Proc Natl Acad Sci U S A 116, 14708-14713.

Santos, J.M., Oudinet, C., Schone, L., Dauba, A., Khamlichi, A.A., 2019b. Essential role of the initial activation signal in isotype selection upon deletion of a transcriptionally committed promoter. Sci Rep 9, 18543. 
Sanyal, A., Lajoie, B.R., Jain, G., \& Dekker, J., 2012. The long-range interaction landscape of gene promoters. Nature 489, 109-113.

Schatz, D.G., \& Ji, Y., 2011. Recombination Centres and the Orchestration of V(D)J Recombination. Nat Rev Immunol. 11, 251-63.

Schoenfelder, S., \& Fraser, P., 2019. Long-range enhancer-promoter contacts in gene expression control. Nat Rev Genet 20, 437-455.

Schwab, K.R., Patel, S.R., \& Dressler, G.R., 2011. Role of PTIP in class switch recombination and longrange chromatin interactions at the immunoglobulin heavy chain locus. Mol Cell Biol 31, 1503-1511.

Seagal, J., Edry, E., Keren, Z., Leider, N., Benny, O., Machluf, M., \& Melamed, D., 2003. A fail-safe mechanism for negative selection of isotype-switched $B$ cell precursors is regulated by the Fas/FasL pathway. J Exp Med 198, 1609-1619.

Seidl, K.J., Manis, J.P., Bottaro, A., Zhang, J., Davidson, L., Kisselgof, A., et al., 1999. Position-dependent inhibition of class-switch recombination by PGK-neor cassettes inserted into the immunoglobulin heavy chain constant region locus. Proc Natl Acad Sci U S A 96, 3000-3005.

Sellars, M., Reina-San-Martin, B., Kastner, P., \& Chan, S., 2009. Ikaros controls isotype selection during immunoglobulin class switch recombination. J Exp Med 206, 1073-1087.

Sexton, T., Yaffe, E., Kenigsberg, E., Bantignies, F., Leblanc, B., Hoichman, M., et al., 2012. Threedimensional folding and functional organization principles of the Drosophila genome. Cell 148, 458472.

Sikorska, N., \& Sexton, T., 2020. Defining Functionally Relevant Spatial Chromatin Domains: It is a TAD Complicated. J Mol Biol 432, 653-664.

Soutourina, J., 2018. Transcription regulation by the Mediator complex. Nat Rev Mol Cell Biol 19, 262274.

Spitz, F., \& Furlong, E.E., 2012. Transcription factors: from enhancer binding to developmental control. Nat Rev Genet 13, 613-626.

Starnes, L.M., Su, D., Pikkupeura, L.M., Weinert, B.T., Santos, M.A., Mund, A., et al., 2016. A PTIP-PA1 subcomplex promotes transcription for IgH class switching independently from the associated MLL3/MLL4 methyltransferase complex. Genes Dev 30, 149-163.

Stavnezer, J., 2000. Molecular Processes That Regulate Class Switching. Curr Top Microbiol Immunol . $245,127-68$.

Stavnezer, J., Bjorkman, A., Du, L., Cagigi, A., \& Pan-Hammarstrom, Q., 2010. Mapping of switch recombination junctions, a tool for studying DNA repair pathways during immunoglobulin class switching. Adv Immunol 108, 45-109.

Stavnezer, J., Guikema, J.E., \& Schrader, C.E., 2008. Mechanism and regulation of class switch recombination. Annu Rev Immunol 26, 261-292.

Storck, S., Aoufouchi, S., Weill, J.C., \& Reynaud, C.A., 2011. AID and partners: for better and (not) for worse. Curr Opin Immunol 23, 337-344. 
Sugiyama, H., Maeda, T., Akira, S., \& Kishimoto, S., 1986. Class-switching from mu to gamma 3 or gamma 2b production at pre-B cell stage. J Immunol 136, 3092-3097.

Swaminathan, S., Klemm, L., Park, E., Papaemmanuil, E., Ford, A., Kweon, S.M., et al., 2015. Mechanisms of clonal evolution in childhood acute lymphoblastic leukemia. Nat Immunol 16, 766-774.

Teng, G., \& Schatz, D.G., 2015. Regulation and Evolution of the RAG Recombinase. Adv Immunol 128, 1-39.

Thomas-Claudepierre, A.-S., Schiavo, E., Heyer, V., Fournier, M., Page, A., Robert, I., \& Reina-SanMartin, B., 2013. The cohesin complex regulates immunoglobulin class switch recombination. J Exp Med 210, 2495-2502.

Thomas-Claudepierre, A.S., Robert, I., Rocha, P.P., Raviram, R., Schiavo, E., Heyer, V., et al., 2016. Mediator facilitates transcriptional activation and dynamic long-range contacts at the IgH locus during class switch recombination. J Exp Med 213, 303-312.

Tung, J.W., \& Herzenberg, L.A., 2007. Unraveling B-1 progenitors. Curr Opin Immunol 19, 150-155.

Vincent-Fabert, C., Fiancette, R., Pinaud, E., Truffinet, V., Cogné, N., Cogné, M., \& Denizot, Y., 2010. Genomic deletion of the whole IgH 3' regulatory region (hs3a, hs1,2, hs3b, and hs4) dramatically affects class switch recombination and Ig secretion to all isotypes. Blood 116, 1895-1898.

Vincent-Fabert, C., Truffinet, V., Fiancette, R., Cogné, N., Cogné, M., \& Denizot, Y., 2009. Ig synthesis and class switching do not require the presence of the hs 4 enhancer in the 3 ' IgH regulatory region. $J$ Immunol 182, 6926-6932.

Volpi, S.A., Verma-Gaur, J., Hassan, R., Ju, Z., Roa, S., Chatterjee, S., et al., 2012. Germline deletion of Igh 3' regulatory region elements hs 5, 6, 7 (hs5-7) affects B cell-specific regulation, rearrangement, and insulation of the Igh locus. J Immunol 188, 2556-2566.

Wang, L., Whang, N., Wuerffel, R., \& Kenter, A.L., 2006. AID-dependent histone acetylation is detected in immunoglobulin S regions. J Exp Med 203, 215-226.

Wang, L., Wuerffel, R., Feldman, S., Khamlichi, A.A., \& Kenter, A.L., 2009. S region sequence, RNA polymerase II, and histone modifications create chromatin accessibility during class switch recombination. J Exp Med 206, 1817-1830.

Wang, Q., Oliveira, T., Jankovic, M., Silva, I.T., Hakim, O., Yao, K., et al., 2014. Epigenetic targeting of activation-induced cytidine deaminase. Proc Natl Acad Sci U S A 111, 18667-18672.

Weake, V.M., \& Workman, J.L., 2010. Inducible gene expression: diverse regulatory mechanisms. Nat Rev Genet 11, 426-437.

White, M.B., Word, C.J., Humphries, C.G., Blattner, F.R., \& Tucker, P.W., 1990. Immunoglobulin D switching can occur through homologous recombination in human B cells. Mol Cell Biol 10, 3690-3699.

Whyte, W.A., Orlando, D.A., Hnisz, D., Abraham, B.J., Lin, C.Y., Kagey, M.H., et al., 2013. Master transcription factors and mediator establish super-enhancers at key cell identity genes. Cell 153, 307319.

Wiedemann, E.M., Peycheva, M., \& Pavri, R., 2016. DNA Replication Origins in Immunoglobulin Switch Regions Regulate Class Switch Recombination in an R-Loop-Dependent Manner. Cell Rep 17, 29272942. 
Wu, Y.L., Stubbington, M.J., Daly, M., Teichmann, S.A., \& Rada, C., 2017. Intrinsic transcriptional heterogeneity in B cells controls early class switching to IgE. J Exp Med 214, 183-196.

Wuerffel, R., Wang, L., Grigera, F., Manis, J., Selsing, E., Perlot, T., et al., 2007. S-S synapsis during class switch recombination is promoted by distantly located transcriptional elements and activationinduced deaminase. Immunity 27, 711-722.

Yamane, A., Resch, W., Kuo, N., Kuchen, S., Li, Z., Sun, H.W., et al., 2011. Deep-sequencing identification of the genomic targets of the cytidine deaminase AID and its cofactor RPA in B lymphocytes. Nat Immunol 12, 62-69.

Yasui, H., Akahori, Y., Hirano, M., Yamada, K., \& Kurosawa, Y., 1989. Class switch from mu to delta is mediated by homologous recombination between sigma mu and sigma mu sequences in human immunoglobulin gene loci. Eur J Immunol 19, 1399-1403.

Yeap, L.S., \& Meng, F.L., 2019. Cis- and trans-factors affecting AID targeting and mutagenic outcomes in antibody diversification. Adv Immunol 141, 51-103.

Yu, K., Chedin, F., Hsieh, C.L., Wilson, T.E., \& Lieber, M.R., 2003. R-loops at immunoglobulin class switch regions in the chromosomes of stimulated B cells. Nat Immunol 4, 442-451.

Yu, K., \& Lieber, M.R., 2019. Current insights into the mechanism of mammalian immunoglobulin class switch recombination. Crit Rev Biochem Mol Biol 54, 333-351.

Zhang, X., Zhang, Y., Ba, Z., Kyritsis, N., Casellas, R., \& Alt, F.W., 2019a. Fundamental roles of chromatin loop extrusion in antibody class switching. Nature 575, 385-389.

Zhang, Y., Zhang, X., Ba, Z., Liang, Z., Dring, E.W., Hu, H., et al., 2019b. The fundamental role of chromatin loop extrusion in physiological V(D)J recombination. Nature 573, 600-604.

Zhang, Z.Z., Hsieh, C.L., Okitsu, C.Y., Han, L., Yu, K., \& Lieber, M.R., 2015. Effect of CpG dinucleotides within IgH switch region repeats on immunoglobulin class switch recombination. Mol Immunol 66, 284289.

Zheng, S., Vuong, B.Q., Vaidyanathan, B., Lin, J.Y., Huang, F.T., \& Chaudhuri, J., 2015. Non-coding RNA Generated following Lariat Debranching Mediates Targeting of AID to DNA. Cell 161, 762-773. 


\section{Figure Legends}

Fig. 1. (A) The mouse $I g H$ locus. The scheme shows a rearranged $I g H$ locus. The cis-acting elements, $\mathrm{E} \mu, 3^{\prime} \gamma 1 \mathrm{E}, 5^{\prime} \mathrm{hs} 1 \mathrm{RI}$ (within $\mathrm{C} \alpha$ gene), 3'RR (3' regulatory region) and the 3' CTCF binding elements ( $\left.3^{\prime} \mathrm{CBEs}\right)$ are indicated. The black arrow indicates transcription from the promoter of the rearranged $V(D) J$ gene. Except for $C \delta$, the $C_{H}$ genes have a similar structure made up of an I promoter immediately followed by an I exon upstream of the highly repetitive $S$ regions, and the $C_{H}$ exons. The blue arrows indicate transcription from $E \mu / I \mu$ enhancer/promoter and $\mid \gamma 1$ promoter that drive transcription of $S \mu$ and $S \gamma 1$ respectively. During CSR, AID targets transcribed S regions (red arrows) initiating DSBs. Repair of the breaks by general DNA repair mechanisms leads to CSR (fused S region ovals, $\mathrm{S} \mu / \mathrm{S} \gamma 1$ in this example). B cell switches from the expression of IgM to a novel class (here IgG1), further diversifying the antibody repertoire and enhancing the robustness of adaptive immune response. Intervening DNA is deleted as an excision circle (right). (B). The human $\lg H$ locus. The locus contains two copies of the $3^{\prime} R R, 3^{\prime} R R 1$ and $3^{\prime} R R 2$. There is no equivalent of the mouse hs $3 b$ at the human 3'RRs. 5'hs1RI is conserved in human $C \alpha 1$ and $C \alpha 2$ genes. IR, inverted repeats.

Fig. 2. The upper scheme shows the relative position of the cis-acting elements and regions that have been mutated in mice. The core enhancer $\mathrm{E} \mu(\mathrm{cE} \mu)$ is flanked by matrix attachment regions (MARs). Within the $3^{\prime} \mathrm{RR}, \mathrm{hs} 1,2$ enhancer lies at the centre of a large palindrome bordered by two copies of hs3 enhancer in opposite orientation. $\beta$-glob stands for the human $\beta$-globin exon that was appended to the mouse l $\alpha$ promoter (see text for details).

The table summarizes the effect of the targeted mutations on GLT and CSR in the mouse and in the $\mathrm{CH} 12$ cell line. \pm indicates low to moderate; the asterisk on $\gamma 2 \mathrm{~b}$ in line $\mathrm{N}$ is to indicate that $S \gamma 2 b$ GLT and IgG2b CSR are reduced in response to LPS, but are unaffected in response to TGF- $\beta$. Sx and IgX stand for $S \gamma 3, S \gamma 1, S \gamma 2 b, S \gamma 2 a, S \varepsilon$ and the corresponding isotypes respectively.

Fig. 3. The multifaceted activity of the $\mathbf{3}^{\prime} \mathbf{R R}$. The $3^{\prime} R R$ mediates silencing of germline transcription associated with $\mathrm{V}(\mathrm{D}) \mathrm{J}$ recombination. Following completion of $\mathrm{V}(\mathrm{D}) \mathrm{J}$ recombination at the $\mathrm{IgH}$ locus, it acts as a constitutive enhancer directed by hs4, prior to 
antigen encounter. Upon B cell activation, the $3^{\prime} R R$ is induced and the four enhancers are highly active.

Fig. 4. Model of the 5 'hs1RI-mediated regulation of $I \gamma 3$ promoter activation. In this speculative model, 5'hs1RI-bound CTCF insulates the 3'RR by forming a loop achor with convergent 3'CBEs-bound CTCF in wild type cells. Upon activation, CTCF is evicted and the $3^{\prime}$ RR can activate $1 \gamma 3$ promoter. In the absence of $5^{\prime} \mathrm{hs} 1 \mathrm{RI}, \mathrm{I} \gamma 3$ is activated prior to $B$ cell activation.

Fig. 5. Cohesin-mediated loop extrusion and class switch recombination centre (CSRC). The

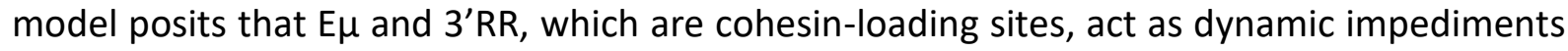
to loop extrusion. Upstream extrusion is dynamically impeded by E $\mu$ region, and downstream extrusion is impeded by the $3^{\prime} \mathrm{RR}$, possibly assisted by the $3^{\prime} \mathrm{CBEs}$ (the impediment is indicated by stop signals). Cohesin is loaded at the enhancers of the $3^{\prime} R R$ and dynamically extrudes $3^{\prime} R R$ chromatin, which align the enhancers as transient loop anchors (not depicted here). Chromatin extrusion juxtaposes $\mathrm{E} \mu$-S $\mu$ with the $3^{\prime} \mathrm{RR}$ (and associated $3^{\prime} \mathrm{CBEs}$ ) to generate a CSRC. Promoters are primed in a stimulation-dependent manner, illustrated here by $1 \gamma 3$ and I 1 promoters following LPS and anti-CD40+IL4 stimulations respectively. Ongoing extrusion brings the associated, highly transcribed $S$ region into close proximity with the $3^{\prime} R R$ in the CSRC. The transcribed S region loads more Cohesin and impedes downstream extrusion, enabling extrusion of upstream chromatin to ultimately align the activated $\mathrm{S}$ region with $\mathrm{S} \mu$. Transcribed S regions recruit AID to initiate CSR (see Zhang et al., 2019a, for a fuller depiction of the model). The role of $3^{\prime} \gamma 1 \mathrm{E}$ and $5^{\prime} \mathrm{hs} 1 \mathrm{RI}$, which are also Cohesin-loading sites, in the process is presently unclear. 
Fig. 1

A

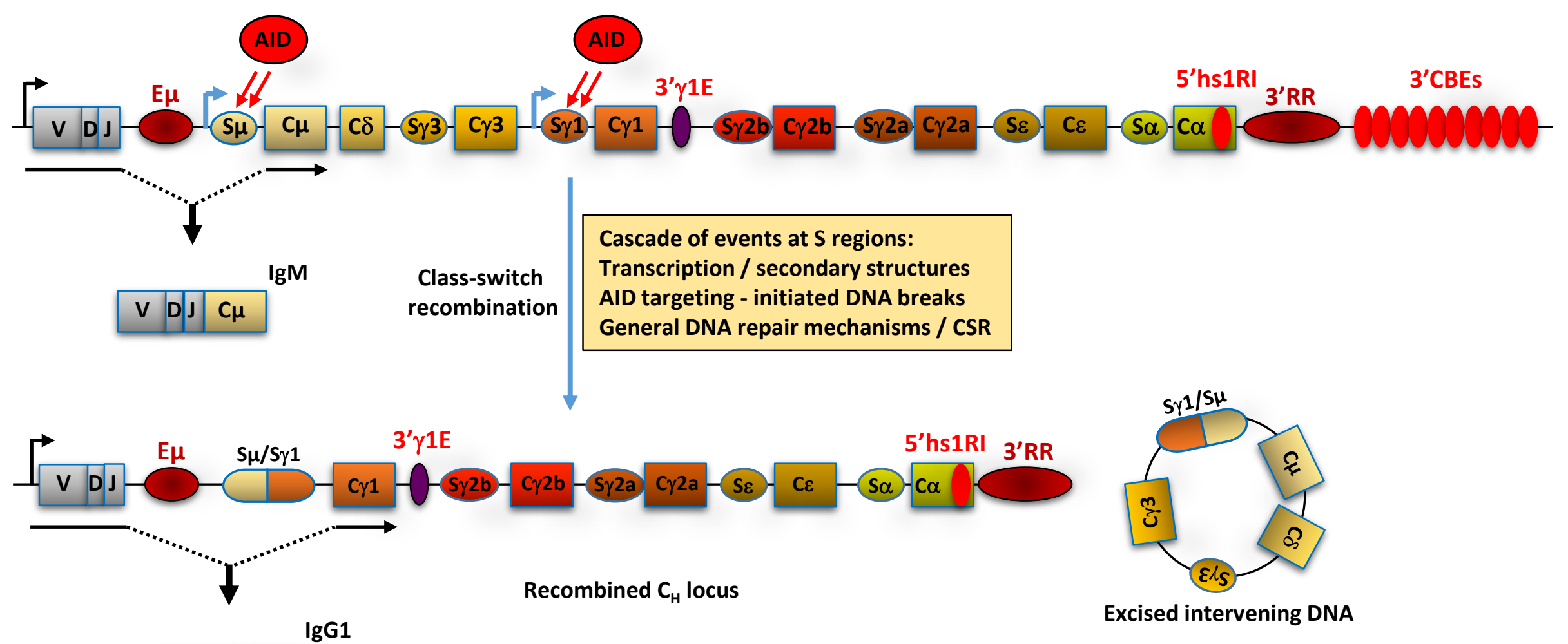

V D J $C_{\gamma} 1$

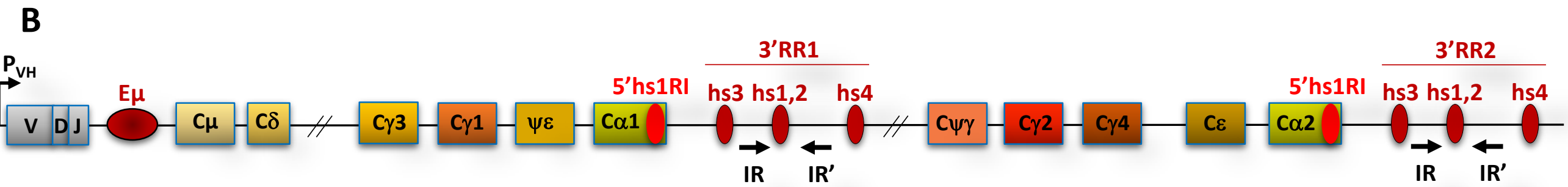




\begin{tabular}{|c|c|c|c|}
\hline Mouse model & GLT at acceptor S regions & Effect on CSR & Reference \\
\hline $\begin{array}{l}\text { A: } \Delta \text { hs1 } \\
\text { B: } \Delta \text { hs1, 2, 3a, 3b cluster }\end{array}$ & $\begin{array}{l}\text { Not assayed } \\
\text { Not assayed }\end{array}$ & No detectable effect & $\begin{array}{l}\text { Perlot et al. } 2010 \\
\text { Perlot et al. } 2010\end{array}$ \\
\hline $\begin{array}{l}\text { C: } \Delta c E \mu \\
\text { D: } \Delta E \mu \text { (cE } \mu+M A R s)\end{array}$ & $\begin{array}{l}\text { Modest effect } \\
\text { Not assayed }\end{array}$ & $\begin{array}{l}\text { Modest effect } \\
\text { Modest effect }\end{array}$ & $\begin{array}{l}\text { Sakai et al., 1999; Perlot et al. } 2005 \\
\text { Sakai et al., 1999; Marquet et al. } 2014\end{array}$ \\
\hline $\mathrm{E}: \Delta 3^{\prime} \gamma 1 \mathrm{E}$ & Decreased $S \gamma 3, S \gamma 2 b, S \gamma 2 a$ & Decreased IgG3, IgG2b, IgG2a & Amoretti-Villa et al., 2019 \\
\hline $\mathrm{F}: \Delta 5^{\prime} \mathrm{hs} 1 \mathrm{RI}$ & $\begin{array}{l}S \gamma 3, S \gamma 2 b, S \gamma 2 a \text { in resting B } \\
\text { Increased } S \gamma 2 b \text { in activated B }\end{array}$ & Decreased IgG3, increased IgG2b & Braikia et al. 2017 \\
\hline $\begin{array}{l}\text { G: } \Delta \text { individual hss } \\
\text { H: } \Delta \text { hs3b and hs } 4 \\
\text { I: } \Delta \text { hs3a-IRIS-hs1,2 } \\
\text { J: } \Delta 5^{\prime} \text { IRIS (inverted residual hs3a) } \\
\text { K: } \Delta \text { palindrome+hs3a, hs1.2, hs3b } \\
\text { L: core 3'RR replacement } \\
\text { M: } \Delta \text { 3'RR }^{\prime}\end{array}$ & $\begin{array}{l}\text { No detectable effect } \\
\text { Decreased (except } S \gamma 1) \\
\text { Decreased } S \gamma 3, S \gamma 2 b, S \gamma 2 a \\
\text { Decreased } S \gamma 2 a \\
\text { Decreased } S \gamma 3, S \gamma 1, S \gamma 2 a \\
\text { Moderate decrease }( \pm S \gamma 1) \\
\text { Strong decrease }( \pm S \gamma 1)\end{array}$ & $\begin{array}{l}\text { No detectable effect } \\
\text { Decreased (except IgG1) } \\
\text { Decreased IgG3, IgG2b, IgG2a } \\
\text { Decreased IgG2a } \\
\text { Decreased IgG3, IgG1, IgG2a } \\
\text { Moderate (except IgG1) } \\
\text { Strong decrease }( \pm \lg G 1)\end{array}$ & $\begin{array}{l}\text { Manis et al. } 1998 \text {; Vincent-Fabert et al. } 2009 \text {; Bébin et al. } 2010 \\
\text { Pinaud et al. } 2001 \\
\text { Saintamand et al., } 2015 \\
\text { Saintamand et al., } 2015 \\
\text { Garot et al. } 2016 \\
\text { Lenoir et al., } 2017 \\
\text { Vincent-Fabert et al. } 2010\end{array}$ \\
\hline $\begin{array}{l}\mathrm{N}: \text { duplication of } \mathrm{l} \alpha \\
\mathrm{O}: \Delta \text { major part of } 3^{\prime} \mathrm{CBES}\end{array}$ & $\begin{array}{l}\text { Decreased } S \gamma 1, S \gamma 2 b^{*}, S \gamma 2 a, S \varepsilon \\
\text { No detectable effect }\end{array}$ & $\begin{array}{l}\text { Decreased IgG1, IgG2b*, IgG2a, IgE, IgA } \\
\text { No detectable effect ( } \pm \text { increased IgG1) }\end{array}$ & $\begin{array}{l}\text { Santos et al., } 2019 \\
\text { Volpi et al. } 2012\end{array}$ \\
\hline $\begin{array}{l}\Delta 3^{\prime} R R \\
\text { Core } 3^{\prime} R R \text { replacement }\end{array}$ & $\begin{array}{l} \pm \text { decreased } \mathrm{S} \alpha \\
\text { No detectable effect on } \mathrm{S} \alpha\end{array}$ & $\begin{array}{l}\text { Decreased IgA } \\
\text { Normal to increased IgA }\end{array}$ & $\begin{array}{l}\text { Kim et al., } 2016 \\
\text { Kim et al., } 2016\end{array}$ \\
\hline$\Delta 3^{\prime} \gamma 1 \mathrm{E}$ & No detectable effect on $\mathrm{S} \alpha$ & Decreased IgA & Amoretti-Villa et al., 2019 \\
\hline$\Delta \mathrm{l} \alpha$ & \pm Increased on $S x$ (abolished for $S \alpha$ ) & \pm Increased $\operatorname{lgX}$ (abolished for $\lg \mathrm{A}$ ) & Santos et al., 2019; Zhang et al., 2019 \\
\hline
\end{tabular}




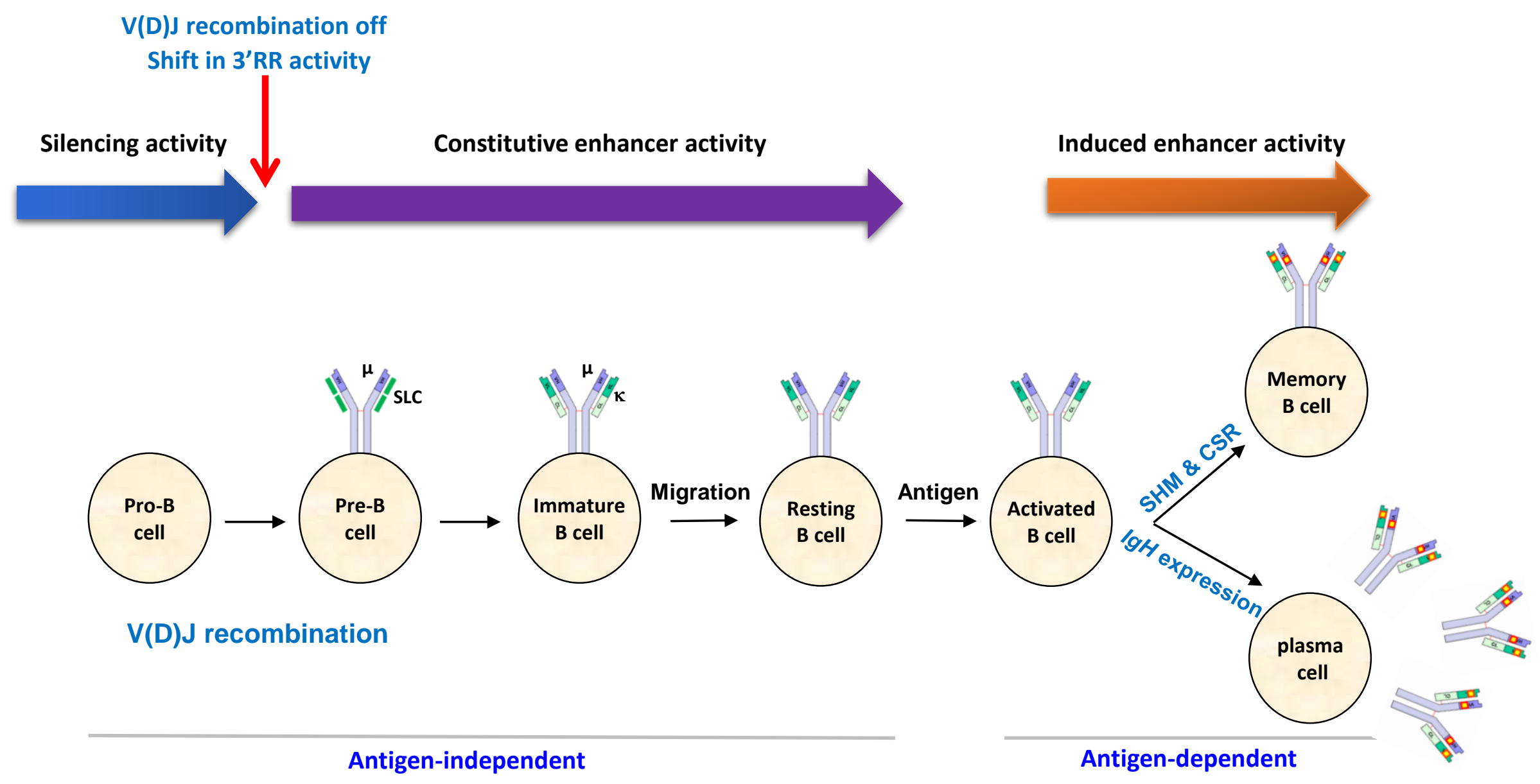


Fig. 4
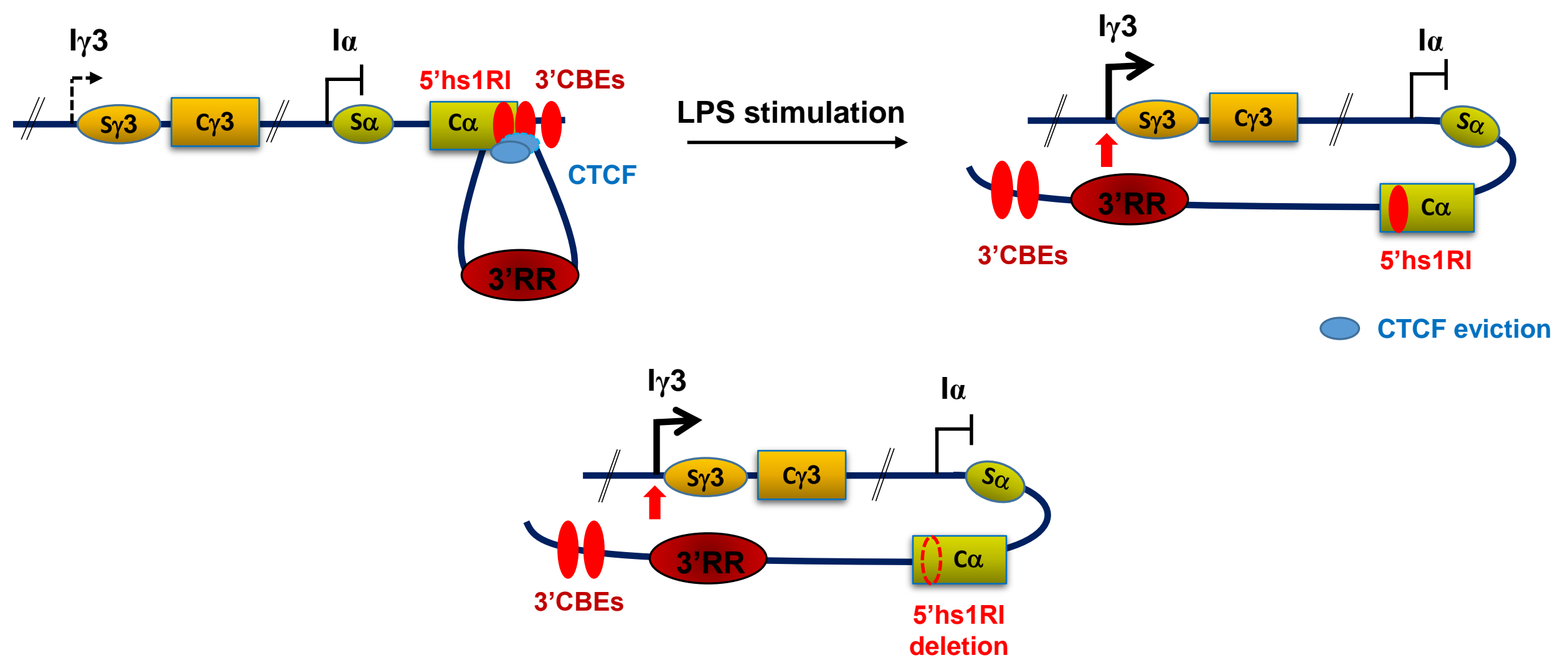

Resting B cells 
Fig. 5

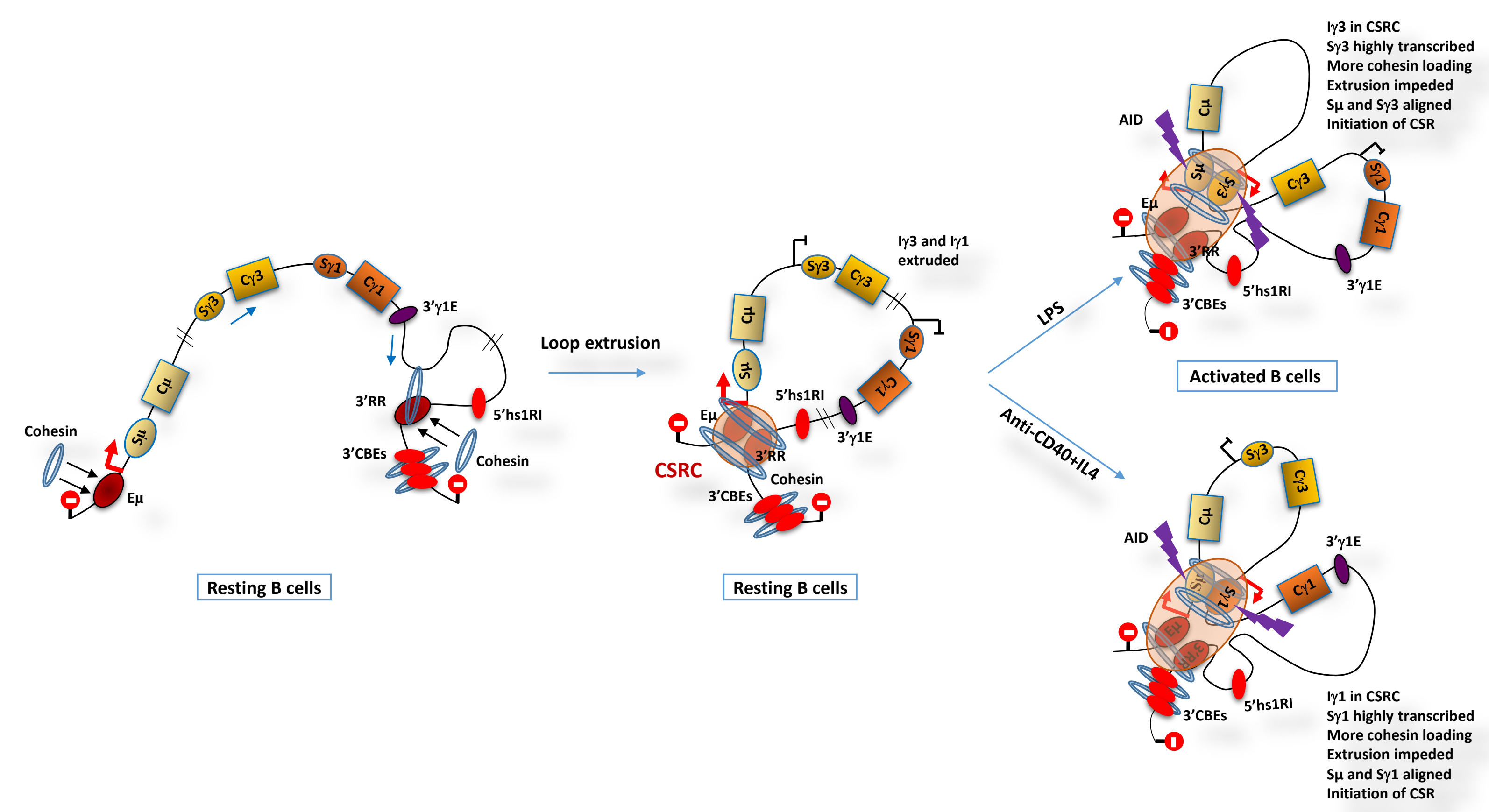

